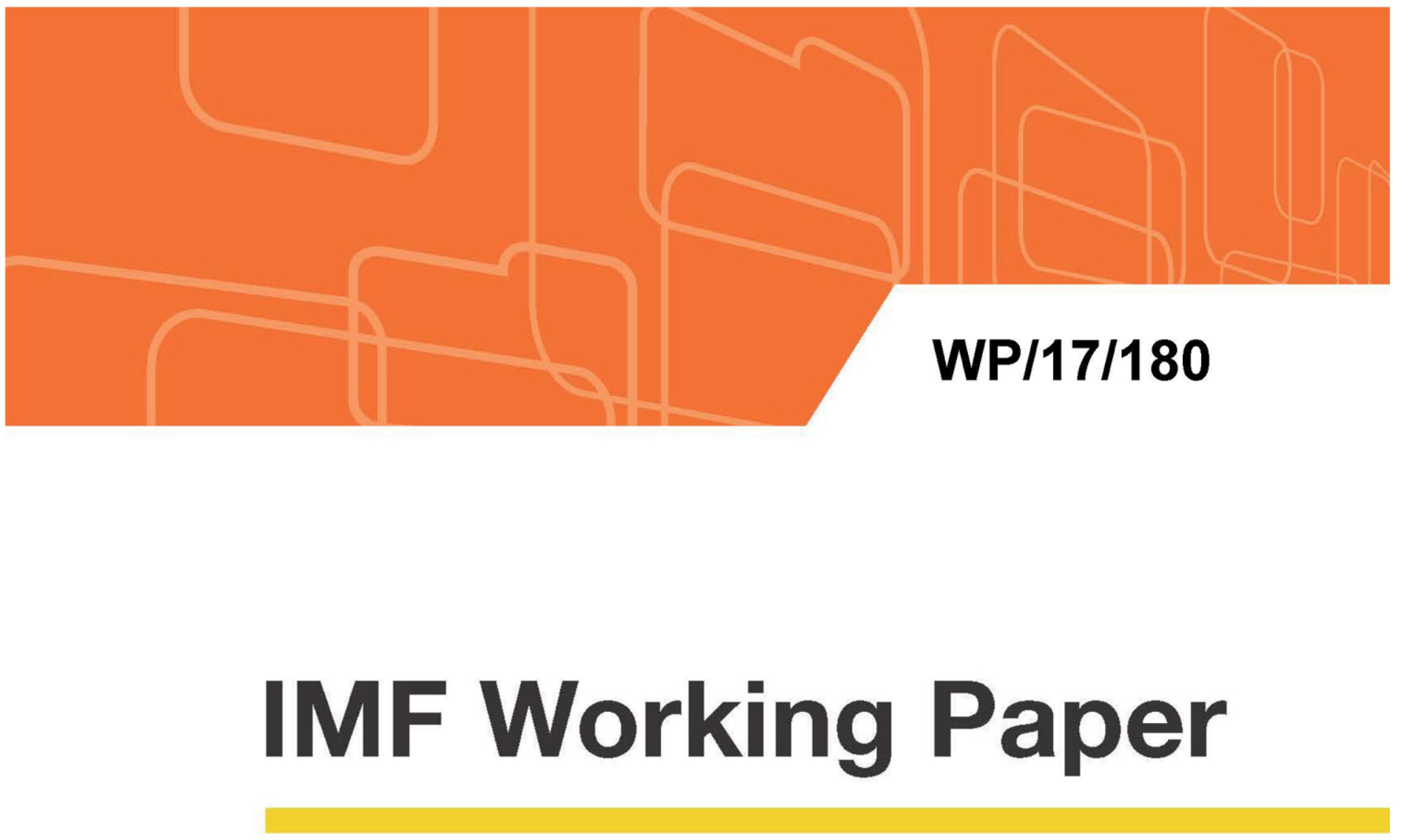

\title{
When Gambling for Resurrection is Too Risky
}

by Divya Kirti

IMF Working Papers describe research in progress by the author(s) and are published to elicit comments and to encourage debate. The views expressed in IMF Working Papers are those of the author(s) and do not necessarily represent the views of the IMF, its Executive Board, or IMF management. 


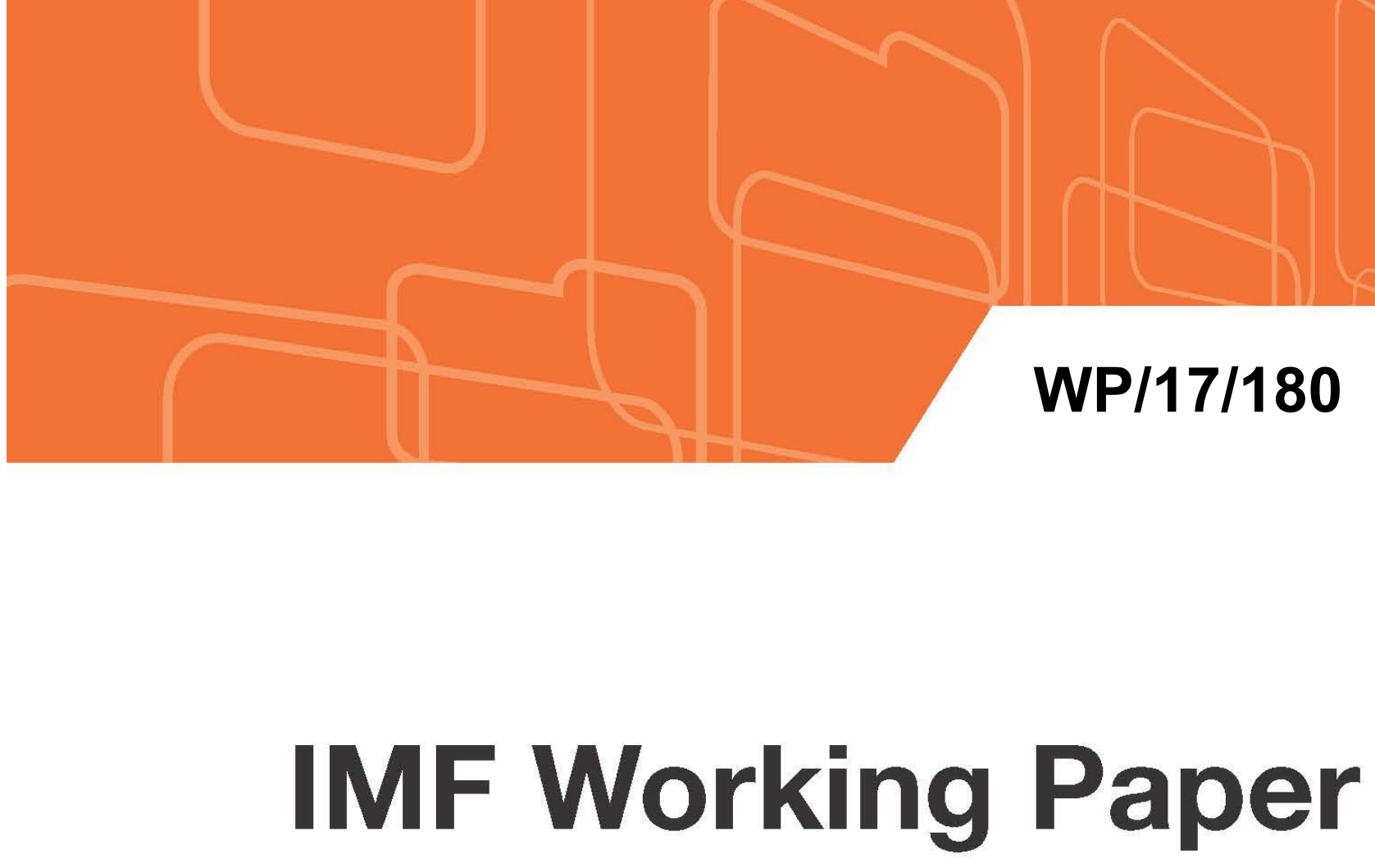

\section{When Gambling for Resurrection is Too Risky}

by Divya Kirti

IMF Working Papers describe research in progress by the author(s) and are published to elicit comments and to encourage debate. The views expressed in IMF Working Papers are those of the author(s) and do not necessarily represent the views of the IMF, its Executive Board, or IMF management.

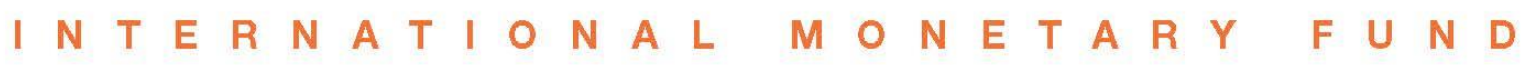




\title{
IMF Working Paper
}

Research Department

\section{When Gambling for Resurrection is Too Risky \\ Prepared by Divya Kirti}

\author{
Authorized for distribution by Maria Soledad Martinez Peria
}

July 2017

\section{IMF Working Papers describe research in progress by the author(s) and are published to elicit comments and to encourage debate. The views expressed in IMF Working Papers are those of the author(s) and do not necessarily represent the views of the IMF, its Executive Board, or IMF management.}

\begin{abstract}
Rather than taking on more risk, US insurers hit hard by the crisis pulled back from risk taking, relative to insurers not hit as hard by the crisis. Capital requirements alone do not explain this risk reduction: insurers hit hard reduced risk within assets with identical regulatory treatment. State level US insurance regulation makes it unlikely this risk reduction was driven by moral suasion. Other financial institutions also reduce risk after large shocks: the same approach applied to banks yields similar results. My results suggest that, at least in some circumstances, franchise value can dominate, making gambling for resurrection too risky.
\end{abstract}

JEL Classification Numbers: G22, G21, G32, G28

Keywords: Life insurance, banking, risk shifting, franchise value, financial frictions Author’s E-Mail Address: dkirti@imf.org 


\title{
When gambling for resurrection is too risky
}

\author{
Divya Kirti*
}

*This paper is a revised version of a chapter in my doctoral thesis at Harvard University titled 'Do financial institutions learn from crises?'. I am deeply grateful to my thesis advisors Jeremy Stein, David Scharfstein, John Campbell, Oliver Hart and Adi Sunderam for their guidance. For helpful conversations, I also thank Giovanni Dell'Ariccia, William Diamond, Benjamin Hébert, Gee Hee Hong, Victoria Ivashina, Maria Soledad Martinez Peria, Vijay Narasiman, Lev Ratnovski, Viktors Stebunovs, Nobuyasu Sugimoto, Yunhui Zhao, and participants at the Macro Financial Modeling Winter 2017 Meeting and the 2017 North American Summer Meeting of The Econometric Society. The views expressed herein are my own and should not be attributed to the IMF, its Executive Board, or its management. 


\section{Introduction}

What drives risk taking by financial institutions? The workhorse corporate finance model, risk shifting, emphasizes incentives for shareholders with limited liability to gamble with creditors' money (Jensen \& Meckling 1976). The literature applies this basic logic to financial institutions in many settings (Stiglitz \& Weiss 1981, Hellmann, Murdock \& Stiglitz 2000, Rajan 2006, Acharya \& Viswanathan 2011, Coimbra \& Rey 2017). Risk shifting is also an important part of corporatefinance based regulatory frameworks: for banking as well as insurance (Rochet 2008, Plantin \& Rochet 2007). What does the risk shifting framework imply when financial institutions face severe negative shocks? It makes a clear prediction: they should gamble for resurrection.

The financial crisis provides a natural setting to assess this prediction. I study how the crisis differentially affected risk taking by US financial institutions hit hard by the crisis. My main results pertain to life insurers. Rather than gambling for resurrection, insurers hit hard by the crisis pulled back from risk taking, relative to insurers hit less hard by the crisis. This behavior suggests that insurers hit hard perceived value from ensuring continued survival, and is consistent with the view that financial frictions can restrain risk taking after negative shocks (Gertler \& Kiyotaki 2010, Gertler \& Karadi 2011, Maggiori 2016, Brunnermeier \& Sannikov 2014, He \& Krishnamurthy 2013). I focus on insurance for two main reasons. First, transaction level data on insurers' investments lets me show risk reduction within assets with identical regulatory treatment, addressing the possibility that capital requirements motivated this risk reduction. Second, my results are unlikely to be driven be moral suasion, given the state level structure of US insurance regulation. However, my results are broader: I apply the same approach to banks, and find similar results. My results suggest that, at least in some circumstances, franchise value can make gambling for resurrection too risky.

I begin by constructing measures of risk taking by life insurers on two key dimensions: credit risk and interest rate risk. I focus on life insurers' general accounts: primarily long-term fixedrate annuities and life insurance liabilities backed by investments in medium to long-term fixed income assets (Berends, McMenamin, Plestis \& Rosen 2013, Seifert 2014, Chodorow-Reich, Ghent \& Haddad 2016). I use rich regulatory data, including bond level data on insurers' quarterly holdings and daily transactions, and contract level data on their interest-rate swaps. For credit risk, following 
Becker \& Ivashina (2015), I look at yields on newly purchased bonds. For net interest-rate exposure, I look at the extent to which aggregated instrument-level interest-rate exposure (DV01) from bonds and derivatives offsets estimates of liability exposure. ${ }^{1}$ I use data from 2005-2014, constructing my baseline measures at a quarterly frequency. I separate my sample period into three sub-periods: pre-crisis (2005Q1-2007Q2), crisis (2007Q3-2010Q4), and post-crisis (2011Q1-2014Q4).

I then analyze how the crisis differentially affected risk taking by insurers hit hardest by the crisis. I restrict attention to roughly the largest 50 insurers. These insurers' risk taking matters. They hold about $\$ 2 \mathrm{TN}$ in bonds, and include insurers designated as systemically important by the US FSOC. I aggregate data to the group level, and identify which insurers were hit particularly hard by the crisis based on information about the corporate parent. I combine information from changes in dividends, equity ratios, and equity issuance during the crisis to categorize insurers into those that were 'hit hard' by the crisis, and those that were hit less hard. I use this categorization to conduct difference-in-difference analysis of risk taking during the crisis.

Large insurers that were hit hard by the crisis pulled back, relative to large insurers not hit as hard by the crisis, suggesting a role for franchise value. Risk shifting incentives would push insurers hit hard by the crisis to increase risk taking. In contrast, I find that insurers hit hard by the crisis pulled back, relative to insurers hit less hard. These insurers took less credit risk (bought bonds with lower yields). They also reduced their net interest-rate exposure, in part by entering into derivatives positions with net asset exposure. ${ }^{2}$ My results suggest insurers perceive franchise value from continued survival. ${ }^{3}$ This is consistent with the recent theoretical macrofinance literature, which emphasizes financial frictions that drive risk reduction after negative shocks (Gertler \& Kiyotaki 2010, Gertler \& Karadi 2011, Maggiori 2016, Brunnermeier \& Sannikov 2014, He \& Krishnamurthy 2013). My results are also consistent with Gilje (2016), who shows that oil and gas firms engage in fewer (risky) exploratory projects when reserves are revalued down.

While franchise value can explain this risk reduction, regulation is an important alternative

\footnotetext{
${ }^{1}$ To my knowledge, prior work has not estimated insurers' interest-rate exposure from bonds and derivatives at the instrument level. Chodorow-Reich et al. (2016) use changes in reported derivatives mark-to-market values. Berends \& King (2015) use assumptions about the distribution of contractual terms.

${ }^{2}$ The literature on how and why financial institutions use derivatives is mixed (Begenau, Piazzesi \& Schneider 2015, Rampini, Viswanathan \& Vuillemey 2015). I show that insurers use receive-fixed swaps to hedge.

${ }^{3}$ Existing illiquid assets, as well as new business, could drive insurers' franchise value (Chodorow-Reich et al. 2016).
} 
explanation to consider. Regulation-based explanations come in two flavors. First, explicit regulation such as capital requirements could drive risk reduction. As insurers hit hard faced bigger shocks, capital requirements may have been closer to binding for them, forcing them to recapitalize. Indeed, while the theoretical macro-finance literature assumes constraints on the value of equity or on equity issuance, Koijen \& Yogo $(2015 a)$ view capital requirements as the practical manifestation of financial frictions for insurers, and show that insurers did take actions during the crisis that improved regulatory capital. Relative to Gilje (2016), a focus on financial institutions may initially seem to be a disadvantage, given the potential contaminating effects of capital requirements. Second, and perhaps harder to rule out, regulators might have differentially pushed insurers hit hard to reduce risk via the broader and less formal supervisory process.

As transaction level data on insurers' investments shows similar risk reduction within assets with identical regulatory treatment, regulatory constraints alone cannot explain my results. This is a key advantage of the insurance setting: it permits analysis of risk taking within regulatory buckets. This added granularity allows me to separate the effect of capital requirements from other motives to reduce risk taking. Using transaction level data at a daily frequency, I analyze purchases of newly issued corporate bonds at the bond level. Focusing on variation within insurers, this approach builds on Becker \& Ivashina (2015), who use quarterly bond level holdings data to compare insurers to other institutional investors. As a fraction of purchases by all large insurers, insurers hit hard accounted for smaller shares of purchases of higher yielding bonds during, but not prior to, the crisis. Importantly, this holds within bonds with the same regulatory treatment. Capital requirements do not explain risk reduction within assets with the same capital requirement. Financial frictions appear to go beyond capital requirements.

The fragmented, state level, structure of US insurance regulation makes it unlikely that my results are driven by moral suasion. US insurers are regulated at the state level, and the top 10 states cover only three quarters of general account assets. Even a group that brings state regulators together to look at large insurers only aims to apply "peer pressure" on the lead regulator (NAIC 2013). The literature also suggests that coordinated moral suasion is unlikely. While most states do follow the same overall template for capital requirements, insurers engage in cross-state 
regulatory arbitrage, and there are important differences in regulatory implementation across states (Becker \& Ivashina 2015, Koijen \& Yogo 2016, Ellul, Jotikasthira, Lundblad \& Wang 2015). Moral suasion would also be more plausible at the asset class level, pushing, for example, for shifts from mortgage-backed-securities (MBS) to corporate bonds. My bond level results hold within corporate bonds, and regulators actually lowered capital requirements for MBS during the crisis (Becker \& Opp 2014, Merrill, Nadauld, Stulz \& Sherlund 2012).

Insurers that ended up being hit hard by the crisis were more willing to take risk prior to the crisis in ways not fully captured by regulation. Insurers that ended up hit hard bought more MBS in 2005 than insurers that ended up hit less hard (the first year covered in my data). In 2005 these MBS were sufficiently highly rated to have the same capital requirements as safe corporate bonds, but were higher yielding than corporate bonds. In subsequent years, these MBS were more likely to be downgraded than corporate bonds. Insurers that ended up hit hard do also differ in other ways: they tend to be larger, and a greater share of their liabilities are annuities. These longterm annuities, which are highly convex, may have motivated the initial MBS purchases (Merrill, Nadauld \& Strahan 2014). This underlines the importance of my bond-level results, which do not rely on estimates of liability interest-rate exposure.

Although my main results focus on insurance, I find similar results from applying the same approach to banks. Large banks hit hard by the crisis also pulled back, relative to large banks not hit as hard by the crisis. I categorize banks into those hit hard and those hit less hard based on changes in dividends and equity ratios during the crisis at the parent level. Banks hit hard by the crisis took less credit risk, as measured by different forms of credit growth. They also took less interest-rate risk: unlike banks hit less hard, banks hit hard did not lengthen asset maturities as rates fell. ${ }^{4}$ My results are therefore broad: they include multiple dimensions of risk taking, and cover institutions holding the vast majority of insurance and banking assets.

Studying insurers and banks together adds to my argument beyond showing the breadth of my results. Most importantly, differences between what is risky for insurers and banks, driven by their liability structure, strengthen my results. Unlike banks, insurers tend to be short duration due to

\footnotetext{
${ }^{4}$ Consistent with these findings, Bidder, Krainer \& Shapiro (2017) show that banks exposed to the oil industry reduce risk following a drop in oil prices.
} 
their long-term liabilities. ${ }^{5}$ Consequently, insurers hit hard by the crisis reduced interest-rate risk by increasing asset duration. In contrast, banks hit hard by the crisis did not take on interest-rate risk, by not increasing asset duration. This suggests that my results actually relate to changes in risk taking. Comparing banks and insurers extends the domain of my results in other ways. For example, banks and insurers may have had different bailout probabilities. Moreover, if franchise value broadly relates to existing illiquid assets rather than the new business, the Chodorow-Reich et al. (2016) 'asset insulator' view of insurers may apply to banks as well, consistent with Hanson, Shleifer, Stein \& Vishny (2015). Perhaps insurers and banks should be studied together more broadly: a unified approach to both yields similar results, and comparing them can be helpful. ${ }^{6}$

My results suggest that, at least in some circumstances, franchise value can make gambling for resurrection too risky. However, in other circumstances, financial institutions (insurers as well as banks) respond to negative shocks by increasing risk taking (Becker \& Ivashina 2015, IMF 2016, Foley-Fisher, Narajabad \& Verani 2016, Eber 2016, Dell'Ariccia, Laeven \& Suarez 2016, Drechsler, Drechsel, Marques-Ibanez \& Schnabl 2016, Plosser \& Santos 2014). How should my results and interpretation be reconciled with this literature? There are two possibilities. First, my results may show a local failure of the workhorse risk shifting framework. Risk shifting may still apply in more 'normal' circumstances. Alternatively, risk shifting might require even larger negative shocks (larger than shocks in the recent crisis, which did differentially affect risk taking by financial institutions hit hard). Second, forces other than risk shifting might explain increased risk taking in response to shocks even in normal circumstances. For example, incentives to smooth earnings, or to reach for yield due to fixed return targets, might drive increased risk taking in response to smaller shocks. For sufficiently large shocks, however, perhaps franchise value dominates.

From a policy perspective, if financial institutions reduce risk in crises in part to preserve franchise value, some macro-prudential efforts to loosen micro-prudential regulation may not be effec-

\footnotetext{
${ }^{5}$ A shortage of long-term bonds with credit risk exposure might push insurers to take risk by being short duration. Also see Berends et al. (2013), Chodorow-Reich (2014), Domanski, Shin \& Sushko (2015), IMF (2016), Hartley, Paulson \& Rosen (2016), Koijen \& Yogo (2015b) and Holsboer (2000).

${ }^{6}$ Comparing insurers and banks also helps identify a role for credit supply during the crisis. Banks and insurers pulled back from risk taking broadly, insurers in ways unlikely to be driven by demand for bank credit. This observation adds to the discussion of why credit fell during the crisis, e.g. Greenstone, Mas \& Nguyen (2014), Mian $\&$ Sufi (2010a) and Mian \& Sufi (2010b).
} 
tive. The macro-prudential paradigm looks to ensure that regulatory efforts designed to safeguard individual financial institutions do not have adverse effects at a macro level (Hanson, Kashyap \& Stein 2011). To be effective, macro-prudential regulation needs to focus on requirements that bind. For instance, time varying capital requirements may not be sufficient if risk reduction is driven by franchise value rather than capital requirements. Actions that make ongoing survival clear, such as stress tests or recapitalization, may be more effective. Relatedly, actions that reduce franchise value may make financial institutions less safe (Sarin \& Summers 2016). More broadly, capital requirements may be less relevant when franchise value is important (Keeley 1990).

The remainder of this paper is structured as follows. Section 2 provides some institutional context. Section 3 describes my data, my measures of risk taking, and how I categorize financial institutions into those hit hard by the crisis, and those hit less hard. Section 4 presents the results: insurers hit hard by the crisis pulled back during and after the crisis. It also discusses bond level results to evaluate the role of regulation, and shows similar results for banks. Section 5 concludes.

\section{Institutional setting}

Life insurers, like banks, are large financial intermediaries that primarily invest in fixed income assets. Figure 1 compares the total balance sheets of life insurers and banks as of 2014 (the last year for which I use institution level data), based on aggregate flow of funds data from the Federal Reserve. Insurers primarily invest in bonds (largely corporate bonds and MBS). Banks mostly invest in loans and bonds (treasuries and MBS). While insurers do have some equity holdings, these are primarily held in separate accounts, backing liabilities such as variable annuities. Insurers' investment behavior matters in aggregate, even relative to banks: in 2014, insurer balance sheets were nearly half as big as bank balance sheets.

I focus on life insurers' general accounts: these should be thought of as pools of medium- to long-term fixed income assets backing a mix of long-term annuity and life insurance liabilities. Life insurers have large investments in corporate bonds (across industries), structured bonds and government bonds. Credit risk is therefore a key dimension of risk for insurers. The majority of 
liabilities are deferred fixed-rate annuities, fixed-rate coupon streams of payments paid for upfront with a period of accumulation, and long-term life insurance contracts. Annuities have grown as a fraction of insurers' liabilities for several decades. Recent growth has been in the form of variable annuities, held in separate accounts (Berends et al. 2013, Seifert 2014, Poterba 1997, ChodorowReich et al. 2016, Becker \& Ivashina 2015, Koijen \& Yogo 2015b).

Insurers have large liability duration exposure, as a substantial portion of their liabilities are long term and fixed rate. Insurers typically do not fully offset interest-rate exposure from their liabilities with asset duration (Berends et al. 2013, Domanski et al. 2015, Chodorow-Reich 2014, IMF 2016, Hartley et al. 2016, Holsboer 2000, EIOPA 2014). When considered together with risk taking by banks, this might seem puzzling. The conventional wisdom is that banks borrow short and lend long, and make money in part by benefiting from an upward sloping yield curve. Why would insurers not want to reduce duration exposure by holding longer term assets with higher yields to boot? One possibility relates to the supply of long-term bonds. If the only issuer of very long-term bonds is the government, issuing safe, low yielding bonds, this may generate incentives to take interest-rate risk along with credit risk. ${ }^{7}$

Like banks, US insurers are subject to risk-based capital (RBC) requirements. An insurance crisis unfolded in parallel to the savings and loans crisis in the late eighties and early nineties, and capital requirements were introduced in their current form for insurers in the mid-nineties (DeAngelo, DeAngelo \& Gilson 1994, Brewer III, Mondschean \& Strahan 1993, Briys \& De Varenne 1997, Foley-Fisher, Narajabad \& Verani 2015). The system is implemented at the state level by state regulators, coordinated by the National Association of Insurance Commissioners (NAIC). The RBC system imposes higher capital requirements for assets with more credit risk via coarse, rating-based, asset categories. State regulators can require corrective action as insurers approach required capital levels. Large insurers deemed to be in trouble can receive attention from a crossstate 'working group' of regulators, which can put peer pressure on the pertinent state regulator to take action (NAIC 2013, FIO 2013, NAIC 2012, Becker \& Ivashina 2015, Becker \& Opp 2014).

\footnotetext{
${ }^{7}$ Market participants argue that accounting treatment discourages hedging via derivatives. Under US GAAP, changes in market values are not recorded for insurers' liabilities, do not enter earnings for bonds (but do affect equity through OCI), and enter earnings directly for derivatives. See, for example, Risk.net, Insurers' losses shine light on swaps accounting, February $201 \%$.
} 
Insurers also face capital requirements for interest-rate risk (AAA 1999, AAA 2014). These are based on stress tests that primarily capture reinvestment risk.

\section{Data}

Focusing on large US life insurers and banks, I construct measures of risk taking along two dimensions: interest-rate risk and credit risk. I use detailed insurance regulatory data (Section 3.1), along with standard bank regulatory data (Section 3.2). I use information at the parent level to categorize which financial institutions were hit hard by the crisis (Section 3.3).

\subsection{Insurers}

I obtain detailed insurance regulatory data from SNL Financial. I use it to construct a view of life insurers' holdings on a quarterly basis, based on position level data on all bonds in the general account, as well as a daily view of transactions, again at the position level. I use this data to construct measures of interest-rate risk and credit risk at the insurer-quarter level. As the same data is available for derivatives at the transaction level, I am able to include derivatives (focusing on interest-rate swaps) in my measure of interest-rate risk. As is typical, less detailed data is available on the liability side. I obtain the data for 2005-2014, therefore covering the crisis as well as periods before and after. I use detailed data on insurer' assets and derivatives positions and a simple approximation on the liability side to measure insurers' net interest-rate exposure. Consistent with the literature, I show that insurers do not fully offset liability-side exposure to interest rates through their assets (Berends et al. 2013, Domanski et al. 2015, Chodorow-Reich 2014, IMF 2016, Hartley et al. 2016, Holsboer 2000, EIOPA 2014). I measure credit risk with the average yields to maturity on bonds purchased by insurers, based on transaction level data.

I focus on life insurance subsidiaries of insurance groups, as categorized by SNL, excluding subsidiaries involved in property and casualty insurance or any other business. ${ }^{8}$ Detailed data is only available for assets held by insurers in the general account, which comprise around half

\footnotetext{
${ }^{8}$ Much of AIG's extraordinary risk taking during the crisis, as documented by McDonald \& Paulson (2015), was housed in AIG Financial Products, and is excluded here.
} 
of insurers' total assets. These assets roughly correspond with insurers' life insurance liabilities primarily long-term fixed rate annuities and life insurance - as opposed to, for example, accident and health insurance. The remaining assets are held in separate accounts and correspond to separate account liabilities such as variable annuities. Within this category, most of the investment is in bonds (see Figure 1).

Using this data, I construct a detailed view of life insurers' assets, beginning with their quarterly holdings. I aggregate the data to the insurer group level, pro-forma based on current ownership structures. I restrict attention to large insurers (top two asset deciles by quarter): 64 insurers that account for $90 \%$ of life insurers' general account bond holdings. I am able to match this to information at the corporate parent level for 50 insurers. ${ }^{9}$ Table 1 shows summary statistics for the sample of 1,701 insurer-quarters. Quarterly data is available on all bonds held, at the CUSIP level (reported on Schedule D) and on all interest-rate derivatives outstanding, at the transaction level (reported on Schedule DB). Within this, I identify and restrict attention to standard singlecurrency interest-rate swaps. Insurance regulatory data also allows me to construct a daily view of transactions in bonds and derivatives. The transaction view only includes changes directly resulting from transactions, and excludes mark to market changes. Mark to market changes are reflected in the quarterly view. Appendix A.1 discusses insurance data further.

To treat bonds and derivatives in a comparable way, I summarize insurers' asset exposure to interest rates with DV01. DV01 refers to absolute change in value when interest rates increase by one basis point (a parallel shift in the yield curve across maturities and credit quality). Bonds held by insurers tend to have duration around 8 years. ${ }^{10}$ To get a sense for magnitudes, consider the case of modified duration of 10 years: this means that when rates rise by $1 \%$, bond values fall by 10\%: a multiplication by 0.1 . The corresponding change for a one basis point shift in rates is a hundredth of this, or a multiplication by 0.001 . Therefore, when total bond values are in trillions of dollars, DV01 tends to be in billions of dollars. To calculate DV01 for derivatives, I price each contract using a log-linearly interpolated swap curve (using data from Bloomberg). Appendix A.1

\footnotetext{
${ }^{9}$ I use data on corporate structures and parents from SNL, supplementing this with information from Compustat. I am unable to match to a corporate parent primarily for mutuals and insurers with private corporate owners.

${ }^{10}$ To simplify the analysis, I do not adjust for prepayment options embedded in MBS.
} 
describes how I classify the direction of insurers' swaps in detail.

As less detailed data is available about life insurers' liabilities, I use a simple approximation to estimate the duration exposure of insurers' liabilities. The only information I can use to construct an estimate of duration on the liability side is the market value of insurers' liabilities. I therefore use a simple assumption: that the average modified duration of these liabilities is 15 years. ${ }^{11}$ This is roughly the duration of a portfolio with a significant share of long-term liabilities, as shown in the table below. The table shows the average modified duration of a portfolio equally spread between bonds with maturities ranging from 10-50 years, with a 5\% coupon and three scenarios for the current interest rate.

Modified duration for bonds with 5\% coupon: maturity and yield scenarios

\begin{tabular}{c|ccc}
\hline Maturity/Yield & $6 \%$ & $4 \%$ & $2 \%$ \\
\hline 10 & 7.6 & 7.9 & 8.2 \\
20 & 11.9 & 13.0 & 14.1 \\
30 & 14.3 & 16.5 & 18.9 \\
40 & 15.5 & 19.0 & 22.9 \\
50 & 16.1 & 20.7 & 26.4 \\
\hline Average & 13.1 & 15.4 & 18.1 \\
\hline
\end{tabular}

I combine insurers' asset and liability exposures to construct their net duration exposure. This includes detailed information on insurers' bond holdings and derivative portfolios. Figure 2 shows the composition of insurers' duration exposure. As discussed in Section 2, insurers do not fully offset liability duration exposure with asset duration exposure. I therefore define the Net DV01 Gap as the gap between liability-side DV01 and the sum of bond and derivatives DV01, as a fraction of liability-side DV01, in percentage points (the green portion of the bars in Figure 2). The Bond DV01 gap is similar, but excludes insurers' derivatives portfolios. Table 1 shows summary statistics for the full sample. DV01 gaps are roughly $40 \%$ on average.

I measure credit risk using the average yield to maturity on bonds purchased by insurers in a given quarter. Following Becker \& Ivashina (2015), I focus on the yields to maturity only of purchased bonds. Using transaction level data, I calculate the average yield to maturity of bonds

\footnotetext{
${ }^{11}$ By making this assumption, I ignore time variation in the duration of liabilities (convexity) as interest rates move. See, for example, Domanski et al. (2015).
} 
purchased at the insurer level in each quarter. This measures risk taking on an ongoing basis, rather than for the slow-moving aggregate balance sheet. Insurers follow a buy and hold strategy, on average holding bonds for four years (Chodorow-Reich et al. 2016). Table 1 shows that the average yield of bonds purchased by insurers over the sample period is $4.6 \%$. To account for variation in the general level of interest rates, I include quarter fixed effects in regressions, and use difference-in-difference specifications.

I also present bond level results based on purchases of newly issued bonds. To do so, I combine data on new issues of corporate bonds and private structured bonds from 2005-2014 from Dealogic with daily, bond level transaction data. I merge these sources of data by the bond's CUSIP. I identify issuers using Dealogic's classification. See Appendix A.1 for more details. Bond level analysis allows me to look at risk taking within regulatory categories.

\subsubsection{Insurers' swap portfolios}

Figure 3 summarizes life insurers' aggregate holdings of interest-rate swaps, for three different quarters in the sample period. Life insurers have large offsetting positions of pay-fixed and receivefixed interest-rate swaps. Their net position is typically in the receive-fixed direction. For example, in 2012 Q2, a total portfolio with notional $\$ 600 \mathrm{BN}$ corresponded to a net receive-fixed position with notional less than $\$ 100 \mathrm{BN}$. Net receive-fixed positions add duration exposure on the asset side for insures. As insurers typically do not fully offset the liability-side exposure, this means that derivatives reduce net interest-rate risk. Figure 3 also shows the 'duration equivalent notional', a corresponding bond portfolio with the same average duration as insurers' bond holdings, in each quarter. In 2012 Q2, the duration equivalent notional was around $\$ 200 \mathrm{BN}$ (in comparison, these insurers held bonds valued at around $\$ 2 \mathrm{TN}$ in their general accounts). I price individual contracts to produce a measure of interest-rate exposure consistent across bonds and derivatives. Prior work uses reported changes in mark-to-market values (Chodorow-Reich et al. 2016), or notional values and assumptions about the maturity and terms (Berends \& King 2015). ${ }^{12}$

Parenthetically, I note that this is one of the few settings in which detailed data is available

\footnotetext{
${ }^{12}$ The NAIC's Capital Markets Bureau publishes reports discussing general trends in insurers' use of derivatives.
} 
on derivatives. BIS statistics show that, as of the first half of 2016, interest-rate derivatives with notional amounts of $\$ 420 \mathrm{TN}$ were outstanding, with a gross market value of $\$ 15 \mathrm{TN}$. Taken at face value, these statistics suggest that the market for interest-rate risk is one of the biggest in the world (flow of funds data shows that the total market value of corporate and foreign bonds is $\$ 12 \mathrm{TN}$ ). The life insurer view of derivatives suggests a different outlook - derivatives account for about $10 \%$ of the exposure of life insurers' general account bonds. While this data is only for insurers in the US, and within that only life insurance subsidiaries, it helps understand how derivatives are used, and how big they are.

\subsection{Banks}

I use bank regulatory data to construct measures of interest-rate risk and credit risk for banks. I base my measures on both holding company level and call report data at a quarterly frequency from 2005-2014. I aggregate the data to the parent level, based on current ownership structures. I restrict attention to banks with more than $\$ 10 \mathrm{BN}$ in assets in $2014 \mathrm{Q} 4$. I require bank regulatory reporting for all 40 quarters in this period, and match this with information on the corporate parent from SNL. Table 8 shows summary statistics for the resulting sample of 54 banks, with 2,144 bank-quarters.

As bank regulatory data is less detailed in some respects than insurance regulatory data, my measures of interest-rate risk and credit risk are cruder for banks. I measure interest rate risk based on the fraction of bank assets with maturity greater than one year. I use call report data to construct my baseline measure: the fraction of loans with maturity greater than one year. ${ }^{13}$ I use credit growth as my measure of credit risk taking by banks. My baseline measure focuses on real estate loan growth (changes in natural logs), using data at the holding company level. Appendix A.2 discusses data on banks in more detail.

\footnotetext{
${ }^{13}$ Constructing net measures of time varying interest-rate exposure for banks is challenging. Estimating changes in deposit pass-through in the recent zero lower bound period would be particularly difficult.
} 


\subsection{Approach}

I use a difference-in-difference strategy to study the differential response of large financial institutions to the crisis. I categorize large financial institutions into those that were hit hard by the crisis, and those that were (in relative terms) not. I use information at the highest corporate parent level to do so, and apply a consistent approach across insurers and banks. I use information about (book) equity ratios, dividends, and, for insurers, equity issuance. With this approach, I look at financial health at the same level of the organization where strategic decisions are made.

I categorize insurers as hit hard by the crisis based on book equity ratios, dividend growth, and equity issuance during the crisis. I use information at the corporate parent level, and therefore exclude insurers with mutual ownership structures from the baseline analysis. Within the sample of large life insurers with matched parents, I look at the distributions of annual dividend growth and changes in book equity to asset ratios from 2008-2010. I also look at whether any equity was issued from 2008-2010. I flag insurers as 'hit hard' by the crisis if dividend growth or changes in equity ratios are below the 10th percentile at any point during this period, or if any equity was issued. This process flags 24 out of the 50 large insurers in my sample with matched parents as 'hit hard' by the crisis. There is some concentration towards larger insurers: AIG, Prudential and Metlife are all flagged. Berkshire Hathaway is not. Table 1 shows summary statistics for insurers separated out by whether they are flagged or not.

I categorize banks as hit hard by the crisis based on book equity ratios and dividend growth during the crisis. As with insurers, within the sample of large banks with matched parents, I look at the distributions of annual dividend growth and changes in book equity to asset ratios from 2008-2010. I flag banks as 'hit hard' by the crisis if dividend growth or changes in equity ratios are below the 10th percentile at any point during this period. I do not separate banks based on equity issuance during the crisis, as almost all large banks issued equity as part of TARP and stress testing. This process flags 25 out of the 54 large banks in my sample with matched parents as 'hit hard' by the crisis. This does not simply separate out the largest banks: Bank of America and Citi are flagged, while JP Morgan and Wells Fargo are not. Table 8 shows summary statistics for banks separated out by whether they are flagged or not. 


\section{Empirical results}

Risk shifting incentives would push financial institutions hit hard by the crisis to increase risk taking. Section 4.1 shows that large insurers hit hard by the crisis instead pulled back from risk taking. Relative to large insurers hit less hard by the crisis, they reduced credit risk and interest-rate risk. This suggests that rather than being willing to gamble for resurrection, insurers perceived value in avoiding failure. Section 4.2 presents bond level results, and discusses evidence of risk reduction within assets with identical regulatory treatment. Sections 4.3 and 4.4 present several additional results for insurers and results for banks.

\subsection{Initial results for insurers}

I present difference-in-difference analysis within large life insurers. I compare differences in evolution of risk taking behavior (interest-rate risk and credit risk) in response to the crisis. Large insurers account for the vast majority of general account life insurance assets. As described in Section 3.3, I identify a subset of large life insurers that were hit hard by the crisis, based on information about the highest corporate parent. I divide the sample into three periods: pre-crisis (2005Q1-2007Q2), crisis (2007Q3-2010Q4), and post-crisis (2011Q1-2014Q4). I follow Becker \& Ivashina (2015) in separating the pre-crisis and crisis periods at 2007Q2.

Table 2 shows the results. My baseline measure of interest-rate risk is the net DV01 gap: the gap between liability and asset DV01 (including derivatives, scaled to be positive), as a fraction of liability DV01, in percentage points. My baseline measure of credit risk is the average yield to maturity of bonds purchased at a quarterly frequency, in basis points. All specifications include insurer-level dummies for crisis experience (crisis-hit flag), as well as interactions of these dummies with crisis and post crisis period. The interactions are the coefficients of interest. All specifications control for size, and include quarter fixed effects. Standard errors are double-clustered by quarter and insurer in all specifications, following Thompson (2011). This accounts for correlation across quarters within insurer, as well as correlation across insurers within quarter. For both types of risk, I also show specifications including both quarter and insurer fixed effects.

Insurers hit hard by the crisis pulled back, relative to insurers not hit as hard. They reduced 
interest-rate exposure and took less credit risk, relative to other large insurers. Both results hold even when both quarter and insurer fixed effects are included, therefore focusing on within quarter and within insurer variation. During and after the crisis, insurers that were hit hard reduced their DV01 gap by 8 percentage points (four-tenths of a standard deviation), and bought bonds yielding on average 30 basis points less (the within quarter standard deviation of this variable ranges from 30-120 basis points over the sample). Quarter fixed effects and a difference-in-difference specification control for changes in the general level of interest rates. Sections 4.2 and 4.3 show that insurers hit hard did not simply buy bonds with less duration, and if anything bought bonds with higher duration.

Figure 4 shows the timing of this variation. Panel A looks at interest-rate risk, and Panel B at credit risk. Both panels show the raw average of my measures of risk taking for insurers hit hard by the crisis and insurers hit less hard. Cutoffs between the three sub-periods are also marked. In the pre-crisis period, both groups of insurers move essentially in parallel. The results on interest-rate risk are driven in part by a convergence between the two groups of insurers, relative to an initial positive gap, leading to a negative difference-in-difference coefficient. Insurers hit hard had lower levels of DV01 gaps in the post-crisis period. Panel B shows a consistent gap in yields of bonds bought by the two groups of insurers starting at the beginning of the crisis, and going through 2012 . The figure also makes clear that the difference-in-difference specification controls for variation in the overall level of interest rates.

Risk shifting incentives should be stronger after more negative shocks. If risk shifting was driving risk taking, insurers hit hard by the crisis should have increased risk taking relative to insurers hit less hard by the crisis. In fact, insurers hit hard by the crisis pulled back relative to insurers hit less hard by the crisis. They took less credit risk, and reduced net interest-rate risk. Results about aggregate risk taking could reflect the need to improve the regulatory capital position. Section 4.2 addresses this possibility by analyzing risk taking within assets with the same regulatory treatment. Stipulating for now that these results reflect more than the effect of capital requirements, they suggest that insurers hit hard by the crisis perceived franchise value from continued survival: a type of 'anti' Jensen \& Meckling (1976) effect. 
The idea that financial institutions have franchise value that might be destroyed in the event of failure is natural. Indeed, financial institutions build their businesses on trust, which is unlikely to survive bankruptcy. It does not now seem an attractive proposition to start a new investment bank named Lehman Brothers, or an insurer linked to an institution that failed. This kind of franchise value relates to the ability to attract new business in the future. New business is not the only potential loss from bankruptcy: managers might obtain private benefits from continued control of the firm. Franchise value might also relate to existing assets. Chodorow-Reich et al. (2016) argue that insurers' long-term liabilities allow them to derive value from investing in illiquid assets and holding them for long periods. As the probability of failure rises, shifting new investments to safer bonds might reduce the likelihood of having to sell existing assets.

My results contradict the view that risk shifting incentives rise smoothly as the probability of failure rises. Rather than increasing risk taking, insurers hit hard by the crisis reduced risk taking, relative to insurers hit less hard. Given a relative increase in the probability of failure for insurers hit hard, these results show risk taking shifted in the opposite direction to the predictions of the risk shifting framework. My results go against the risk shifting framework even if insurers perceived no possibility of failure: in this case there should be no difference in risk taking between insurers hit hard and insurers hit less hard. Insurers hit hard faced large negative shocks: they reduced dividends by more than $50 \%$, or their book equity fell by more than $25 \%$, or they issued equity during the crisis. The literature also shows that insurers faced substantial negative shocks. Chodorow-Reich (2014) shows CDS spreads for certain large insurers spiked to nearly 3,000 basis points during the crisis. Koijen \& Yogo (2015a) show that insurers offered annuities and life insurance policies that had a positive effect on capital at deep discounts during the crisis. Cooper, Andre, Gabovich \& Pomerantz (2010) point out that unrealized losses were large relative to insurers' equity buffers.

Risk shifting may, however, be relevant in other circumstances. The narrowest interpretation of my results is that risk shifting fails for these specific shocks, in the context of a crisis. This workhorse corporate finance model may apply in more 'normal' circumstances, for smaller, idiosyncractic shocks. Indeed, an empirical literature does suggest that financial institutions increase risk in 
response to negative shocks in other circumstances (Becker \& Ivashina 2015, IMF 2016, FoleyFisher et al. 2016, Eber 2016, Dell'Ariccia et al. 2016, Drechsler et al. 2016, Plosser \& Santos 2014). Alternatively, risk shifting may require even larger shocks than those I study here, as risk shifting incentives may not rise smoothly with the probability of failure, or quantitatively matter only when failure is even more imminent. ${ }^{14}$ More subtly, contracting arrangements that anticipate agency conflict might prevent risk shifting from emerging in equilibrium, as in the theoretical macrofinance literature (Gertler \& Kiyotaki 2010, Gertler \& Karadi 2011, Maggiori 2016, Brunnermeier \& Sannikov 2014, He \& Krishnamurthy 2013). Yet another possibility, as Eber (2016) argues, is that forces other than risk shifting, such as incentives to smooth earnings, drive increased risk taking in other circumstances. Whether and when risk shifting incentives actually dominate affects how financial institutions should be regulated (Rochet 2008, Plantin \& Rochet 2007). Indeed, mitigated risk shifting incentives are sometimes viewed as an important benefit of higher capital requirements (Dagher, Dell'Ariccia, Laeven, Ratnovski \& Tong 2016, Marcus 1984, Esty 1998, Hellmann et al. 2000, Matutes \& Vives 2000, Repullo 2004).

\subsection{The role of regulation}

While franchise value might explain why insurers hit hard pulled back, a natural alternative explanation is based on regulation. Regulation might refer to both formal rules and informal actions from regulators. Most directly, capital requirements might become effectively more binding for financial institutions facing larger shocks, driving risk reduction. This is typically difficult to rule out: while risk reducing actions may have other motivations, they do also alleviate pressure from capital requirements. I focus on insurance as it provides a nice setting in which the effect of capital requirements can, at least to some extent, be excluded. The fragmented nature of insurance regulation in the US also makes it unlikely that moral suasion drives my results.

One regulatory explanation for my results is based on capital requirements. As discussed in Section 2, insurers are subject to risk based capital requirements. Capital requirements are applied consistently across insurers, and were not raised for insurers hit hard by the crisis. However, even

\footnotetext{
${ }^{14}$ Zentefis (2014) suggests that if risk shifting and private benefits are both present, risk shifting may only dominate when failure is imminent.
} 
if capital requirements themselves remained the same, insurers hit hard faced larger shocks. This might have made capital requirements effectively more binding for insurers hit hard. Incentives to recapitalize, rather than general risk reduction, might have pushed insurers hit hard to reduce risk. This explanation is typically difficult to rule out when analyzing risk taking by financial institutions. Most forms of risk reduction do also serve to make capital requirements less binding.

A key advantage of the insurance setting is that it allows analysis of risk taking within regulatory buckets. Insurance regulatory data includes information on holdings and transactions at the bond level. As risk based capital requirements for insurers are based on coarse, rating-based, buckets, variation in risk can be observed within sets of assets with identical regulatory treatment. This allows regulation and other motives for risk taking to be separated. Becker \& Ivashina (2015) exploit this variation to show that insurers reach for yield within regulatory buckets, relative to mutual funds and pension funds.

I present within insurer variation at the bond level to look at the relative evolution of risk taking by insurers hit hard. Section 4.1 shows that insurers hit hard by the crisis bought lower yielding bonds during and after the crisis. Here I look at which bonds insurers hit hard bought during the crisis, and show that these insurers accounted for a smaller share of purchases of higher yielding bonds during and after the crisis. The dependent variable is purchases (at the bond level, for newly issued bonds, close to issuance) by insurers hit hard by the crisis, as a fraction of purchases by all large insurers in my sample with matched parents. I construct this dependent variable using daily transaction level data. Despite focusing on transactions close to issuance for newly issued bonds, I am able to use more than 85,000 individual transactions. ${ }^{15}$ As before, I present specifications that include interactions of variables of interest with dummies for the crisis and post-crisis periods. Regressions therefore show tests for whether differences between insurers' purchasing behavior in the pre-crisis and the crisis and post-crisis periods are statistically significant. All specifications include month and issuer fixed effects, with standard errors clustered by both month and issuer. ${ }^{16}$ I also control for bond maturity and other bond characteristics (total bond purchases and bond

\footnotetext{
${ }^{15}$ See Section 3 and Appendix A.1.3 for details on data construction.

${ }^{16}$ Eber (2016) finds that when credit spreads are low insurers tend to buy riskier bonds. Including time fixed effects controls for changes in the behavior of insurers hit hard relative to insurers let hard over time.
} 
type). This approach builds on Becker \& Ivashina (2015), but focuses on variation within insurers.

Table 3 presents the main bond level results. The sample here covers investment grade corporate bonds (excluding financial issuers) issued from 2005-2014 with at least 10 transactions by large insurers with matched parents within three months of the first insurer transaction. Investment grade (NAIC 1 and 2) corporate bonds excluding financial issuers comprise the bulk of insurers' general account assets (Chodorow-Reich et al. 2016). The first column shows all investment grade corporate bonds. Relative to the pre-crisis period, insurers hit hard accounted for lower fractions of purchases of newly issued bonds during and after the crisis. The effect of yields on the relative purchasing behavior of insurers hit hard is strongly statistically significant both during and after the crisis. This confirms results from Section 4.1 at the bond level. These bond level results hold the asset class of investment fixed, and do not rely on estimates of liability duration.

Capital requirements alone cannot explain risk reduction by insurers hit hard: bond level results show risk reduction within assets with identical regulatory treatment. The second and third columns show only NAIC 1 (AAA to A) and NAIC 2 (BBB+ to BBB-) corporate bonds respectively. Importantly, insurers hit hard reduced risk taking within NAIC categories. These columns restrict the sample to corporate bonds with the same risk-based capital requirement (Cooper et al. 2010, Becker \& Ivashina 2015, Becker \& Opp 2014). Risk reduction within bonds with the same capital requirement cannot be explained by changes in the tightness of capital requirements. Statistical and economic significance is strongest for NAIC 1 corporate bonds. Relative to the pre-crisis period, during and after the crisis the share of purchases by insurers hit hard was 22-30 percentage points lower (about one to one and a half standard deviations), for a bond with a one percentage point higher yield (less than one standard deviation).

My bond level results also hold if I broaden the sample to include financial issuers and private structured bonds. Table 4 presents this analysis. These results show a similar pattern. As with corporate bonds statistical significance is stronger for NAIC 1 bonds and post-crisis. Becker \& Ivashina (2015) find that insurers reached for yield less, relative to other institutional investors, during the crisis. My results are consistent with, and perhaps explain, this finding (insurers hit hard tended to be larger). The first columns of Tables 3 and 4 do also show risk reduction across 
NAIC categories, which could be motivated by capital requirements.

This evidence shows that financial frictions that push towards risk reduction after negative shocks go beyond regulatory constraints. The recent theoretical macro-finance literature emphasizes financial frictions, sometimes explicitly phrased as franchise value constraints, which drive (attempted) risk reduction after negative shocks (Gertler \& Kiyotaki 2010, Gertler \& Karadi 2011, Maggiori 2016, Brunnermeier \& Sannikov 2014, He \& Krishnamurthy 2013). In practice, however, these constraints could just capture capital requirements, as in Koijen \& Yogo (2015a). My results suggest that franchise value can drive risk reducing actions that do not affect regulatory constraints.

Explicit regulation is not the only explanation with a role for regulators. Regulators might also have pushed insurers hit hard to reduce risk in informal ways. Indeed, (NAIC 2013) notes that US "regulators do not use [Risk-Based Capital] ... in isolation." As insurers hit hard reduced risk relative to insurers hit less hard by the crisis, a general effort by regulators to reduce risk is not sufficient to explain my results. However, regulators may have focused particularly on insurers hit hard by the crisis. It is not easy to definitively rule out a specific focus by regulators on insurers hit hard by the crisis.

The fragmented, state level, structure of US insurance regulation makes moral suasion unlikely. Before, during, and after the crisis, US insurers were and are regulated at the state level. This means that more than fifty separate insurance commissioners determine how to regulate insurance subsidiaries in their states. Assets are not highly concentrated by state. The top 10 states only cover three quarters of general account assets for large life insurers with matched parents. For moral suasion to explain my results, these separate regulators would have had to closely coordinate their efforts. While most states do seem to follow a similar template for capital requirements (Becker \& Ivashina 2015), coordination in other dimensions is less likely. For example, the Financial Analysis Working Group, which brings together regulators from multiple states to assess "nationally significant insurers" is limited to applying "peer pressure" on the lead regulator (NAIC 2013). The literature also documents important differences across states, with differences in the extent to which marking to market is enforced and opportunities for cross-state regulatory arbitrage (Ellul et al. 2015, Koijen \& Yogo 2016). 
If moral suasion does play a role in explaining my results, it takes an unusual form. Moral suasion is more likely across asset classes, with regulators suggesting, for example, a shift away from mortgage backed securities that turned out to be risky. I show risk reduction at the bond level within investment grade corporate bonds. Moreover, capital requirements were lowered, not raised, for MBS during the crisis (Becker \& Opp 2014, Merrill et al. 2012). It is also worth noting that a regulatory push across the board to reduce risk would not have been ideal from a macroprudential perspective.

\subsection{Additional results for insurers}

Insurers that ended up being hit hard by the crisis took more risk prior to the crisis. Specifically, insurers hit hard bought substantially more mortgage-backed securities (MBS) in 2005 than insurers not hit has hard by the crisis. Figure 5 shows the path of net purchases for private structured bonds and agency bonds for insurers hit hard (Panel A) and insurers not hit as hard (Panel B). Figure 5 is based on daily transaction level data. Purchases are scaled by total net purchases from 2005-2014, and exclude prepayments. ${ }^{17}$ Insurers hit hard by the crisis bought more MBS than insurers not hit hard in 2005. They did not substantially add to their private structured bond portfolios in subsequent years.

While MBS had higher yields than corporate bonds insurers bought in 2005, and had similar rating distributions to corporate bonds in 2005, MBS were much more likely to be downgraded in subsequent years. This suggests that insurers hit hard by the crisis took risk ex-ante in ways not fully captured by regulation. Figure 6 shows the rating distribution of private structured bonds bought in 2005 by insurers hit hard. Ratings are shown for two years: 2005, and 2009. The distribution is weighted by purchases in 2005, and does not reflect any rebalancing. The safest category, NAIC 1 , is omitted (but can be inferred from the totals in the remaining categories). These MBS were very likely to subsequently be downgraded, sometimes substantially (Coval, Jurek \& Stafford 2009). Corporate bonds were much less likely to be downgraded as severely. Insurers did not have to put up substantially more capital for MBS - capital requirements for MBS were lowered during the

\footnotetext{
${ }^{17}$ I identify prepayments using date patterns and text descriptions of transactions. See Appendix A.1.3.
} 
crisis (Becker \& Opp 2014, Merrill et al. 2012).

The key difference between insurers hit hard and insurers hit less hard is the extent to which they bought MBS in 2005, and not risk taking within MBS. Figure 6 shows the distribution based on purchases by insurers hit hard. The evolution of ratings is quite similar for MBS bought by insurers hit hard (not shown). The primary difference is that insurers hit hard bought more MBS (Figure 5). Insurers hit hard tend to be somewhat larger and have a higher share of liabilities in the form of annuities. As Merrill et al. (2014) point out, a higher annuity share might motivate greater risk taking because of the strong convexity of long-term bond-like liabilities. However, this difference in liability structure does not imply any particular need to reduce risk taking after a negative shock.

Derivatives play an important role in insurers' interest-rate risk management strategy. Insurers hit hard by the crisis reduced exposure to interest rates by adding traditional asset duration as well as entering into receive-fixed swaps positions. As I estimate duration on the liability side in a simple manner with a single duration estimate, time series variation on the liability side is driven by changes in the recorded value of liabilities rather than movements in duration in response to changing interest rates. My baseline results focus on net interest-rate exposure. Table 5 shows results for insurers separating out the effect of derivatives. It repeats my baseline results on interestrate risk, and then also shows results based on net duration exposure excluding derivatives (Bond DV01 gap rather than Net DV01 gap). Derivatives are an important component of reduced interestrate exposure for insurers hit hard by the crisis. In terms of magnitude, derivatives account for more than half of the difference-in-difference coefficient.

A potential concern about my initial results for insurers is that they might conflate buying shorter-term bonds with buying bonds with less credit risk. I define my measure of credit risk for insurers as the average yield of all bonds purchased in a given quarter. Yield to maturity depends on the level of risk, but also on general interest rates and maturity/duration. As I use differencein-difference specifications with quarter fixed effects, changes in the general level of interest rates are accounted for. However, if insurers hit hard by the crisis bought bonds with lower maturities, average yields could be lower even if there was no change in credit risk. Bond level results already 
address this concern by controlling for maturity explicitly. Table 6 further addresses this concern. It reproduces my baseline results on credit risk from Table 2 and also shows specifications where the dependent variable is the average duration of all bonds bought at a quarterly frequency. If anything insurers hit hard bought longer-term, not shorter-term, bonds during and after the crisis.

If insurers shifted purchases to bonds with more duration exposure, could the interest-rate risk component of capital requirements have a role to play in explaining my results? No: Tables 3 and 4 show that even with explicit controls for maturity, insurers hit hard by the crisis accounted for a smaller share of purchases of high yielding bonds during and after the crisis. As discussed in Section 2, risk-based capital requirements (RBC) are only one component of capital requirements for insurers. Other components take other inputs, including interest-rate risk. Even if the interestrate risk component of capital requirements strongly penalized interest-rate risk, it would only incentivize buying bonds with more duration, not safer bonds. A subtle aspect of this argument is that it only applies within asset class. A push to increase duration across asset classes might lead to shifts from corporate bonds (mostly issued at medium-term maturities) to long-term treasury bonds, which would necessarily be lower yielding and not just provide more duration exposure. It is therefore important that my results hold within corporate bonds.

My baseline results for insurers focus on difference-in-difference specifications for the sample of

large insurers where I am able to match to information about the corporate parent. My results are robust to including all large insurers instead. As I do not have information about the corporate parent (dividends, equity ratios and equity issuance) that would allow me to categorize unmatched insurers, I classify them as insurers not hit hard. Table 7 shows the results. While the magnitudes are somewhat smaller, and statistical significance is attenuated for credit risk, the results are robust to including all large insurers in the regressions.

\subsection{Results for banks}

I focus on insurers because data availability and features of the institutional setting for these financial institutions sharpen my results and their interpretation. My results are, however, broader. I apply the same approach I take with insurers to banks, and find similar results for banks. As 
described in Section 3.3, I identify a subset of large banks that were hit hard by the crisis, based on information about the highest corporate parent. Large banks hit hard by the crisis also pulled back from risk taking, relative to banks not hit as hard by the crisis.

Table 9 shows the results for banks. My baseline measure of credit risk for banks is credit growth: specifically, natural log changes in real estate loans (BHC data), multiplied by 100. My baseline measure of interest-rate risk for banks is the fraction of loans with maturity greater than one year (call report data), in percentage points. This is the type of variable flagged in recent FDIC warnings that banks are taking on more interest-rate risk. I structure the regressions in exactly the same way as the corresponding analysis for insurers (Table 2). Again, I control for size directly, and include quarter fixed effects in all specifications. Standard errors are double clustered.

Paralleling the results for insurers, large banks that were hit hard by the crisis pulled back, relative to banks not hit as hard. Their credit portfolios grew slower, and they did not extend asset maturities post-crisis. During the crisis, real estate loan portfolios grew by one percentage point per quarter less for banks hit hard (a third of a standard deviation). Post crisis, banks that were hit hard increased their loan maturities less. Figure 7 shows the timing of this variation. Again, Panel A looks at interest-rate risk, and Panel B at credit risk. Panel A shows that, within large banks, almost all maturity extension is concentrated within banks that were not hit as hard during the crisis. The difference-in-difference coefficient is more than a third of a standard deviation. Both panels show that the two groups of banks moved in parallel pre-crisis. Section 4.3 shows that banks hit hard by the crisis also reduced their holdings of long-term securities.

I undertake three robustness exercises for banks. First, Table 10 shows that they apply to total lending as well as real estate lending. This also shows that my results are not driven by changes in loan loss provisions: total loans are reported net of loan loss provisions on call reports, while components of lending are reported without deducting loan loss provisions (see Appendix A.2). Second, parallel trends in loan growth shown in Panel B of Figure 7 extend back to 2000. Third, TARP issuance and repayment did not differentially affect risk taking by banks hit hard. ${ }^{18}$

Comparing insurers and banks adds to my argument beyond showing the breadth of my results.

\footnotetext{
${ }^{18}$ Figures and tables are available on request.
} 
Most importantly, differences in liability structure mean that insurers and banks take interest-rate risk in different ways. As discussed in Section 2, insurers are likely to take interest-rate risk by not fully offsetting liability duration exposure. Banks are likely to take interest-rate risk by lengthening asset maturities while still borrowing short. Given these different initial exposures, reducing risk also means different things for insurers and banks. Large insurers hit hard by the crisis reduced interest rate risk by increasing asset duration, thereby reducing the gap to their liability duration. Large banks hit hard by the crisis, in contrast, took on less interest rate risk by not increasing asset duration. This shows that large financial institutions really did reduce risk - based on the appropriate definition of risk. That these shifts imply moves in opposite directions helps address concerns that would arise in looking at one sector in isolation, even with difference-in-difference analysis. Specifically, this shows that neither sector was taking directional bets on interest rates.

Other differences between insurers and banks also help interpret my results. Given the different regulatory structures and prominence for insurance and banking, one might have expected different bailout probabilities in these two sectors. My results apply to both. This addresses concerns, for example, that insurers would have taken more risk if they had higher bailout probabilities. Similarly, insurers' and banks' differing liability structures might be informative about what franchise value means. My results for insurers might show franchise value arising from existing assets under the Chodorow-Reich et al. (2016) asset insulator view. As franchise value seems relevant for both insurers and banks, perhaps banks are asset insulators as well. This is consistent with the Hanson et al. (2015) argument that banks' stable deposit funding might match well with assets prone to fire sales.

I find evidence that insurers and banks hit hard by the crisis pulled back broadly from risk taking. This adds to the discussion of why credit supply fell during the crisis (Greenstone et al. 2014, Mian \& Sufi 2010a, Mian \& Sufi 2010b), by suggesting a role for the effects of reduced risk taking by banks on credit supply. The magnitude of risk reduction is large. The difference in real estate loan growth between banks hit hard and banks hit less hard can account for about half of the total reduction in real estate lending during the crisis. Both insurers and banks hit hard by the crisis reduced risk taking on multiple dimensions of risk taking. Insurers hit hard reduced risk by 
shifting asset allocations within safe corporate bonds, relative to insurers hit less hard by the crisis. Drivers of bank credit demand, particularly consumer credit demand, are unlikely to drive my bond level results for insurers. Comparing banks with other institutional investors might provide a conceptual alternative when the standard approach to identifying credit supply, analyzing lending by a single bank to multiple firms (Khwaja \& Mian 2008), is hard to implement.

All of this suggests that comparing insurers and banks might be valuable. Life insurers and banks do differ in important ways. However, as outlined above, some differences such as liability and regulatory structure can make comparisons between the two more informative. Moreover, life insurers and banks are similar in many ways. They are large financial institutions that invest primarily in fixed income assets, which makes them important providers of credit. They share key dimensions of risk, including credit risk and interest-rate risk. Both are subject to risk-based capital requirements. And a unified approach applied to both insurers and banks yields consistent results: financial institutions hit hard during the crisis pulled back from risk taking.

\section{Conclusion}

Risk shifting, the workhorse corporate finance model for thinking about risk taking by financial institutions, predicts that they should gamble for resurrection after large negative shocks. However, I find that large life insurers hit hard by the crisis actually pulled back from risk taking, relative to insurers hit less hard by the crisis. Insurers hit hard took less credit risk as well as less interest-rate risk. My results suggest that franchise value can, at least in some circumstances, make gambling for resurrection too risky.

Insurance provides a nice setting to analyze risk taking by financial institutions: regulation is unlikely to drive my results. Scope for analysis within regulatory buckets is a key advantage of this setting, and allows me to separate the effect of capital requirements from other motivations to reduce risk taking. Bond level results using transaction level data show that insurers took less credit risk within newly issued corporate bonds with the same capital requirement. Capital requirements alone therefore cannot explain my results. My results suggest that financial frictions 
go beyond capital requirements. Moreover, the state level structure of US insurance regulation makes it unlikely that moral suasion drives my results.

While my results are sharpest for insurance, a similar approach yields similar results for banks. Large banks hit hard by the crisis also pulled back from risk taking. Differences in the way banks and insurers take interest-rate risk show that my results pertain to risk taking, as reducing risk means different things for banks and insurers. Perhaps insurers and banks should be studied together more broadly. Despite their differences, which can in themselves make this comparison valuable, they do share important similarities. In particular, both play an important role for credit supply.

I show that large US financial institutions hit particularly hard by the crisis pulled back from risk taking. When facing failure, franchise value seems to be an important force that discourages risk taking. This is not inconsistent with incentives to increase risk in response to other shocks, such as reaching for yield in response to persistently low interest rates. Indeed, the literature does show increased risk taking in other circumstances (Becker \& Ivashina 2015, IMF 2016, Foley-Fisher et al. 2016, Dell'Ariccia et al. 2016, Drechsler et al. 2016, Plosser \& Santos 2014). As far as the workhorse risk shifting framework goes, one possibility is that I document a local failure of the model, in the region of certain large shocks. Another possibility is that incentives other than risk shifting drive increased risk taking in other circumstances as well. For example, incentives to smooth earnings, or fixed return targets, can also explain increased risk taking in response to smaller shocks.

If franchise value does deter risk taking in some circumstances, this has implications for macroprudential policy. A macro-prudential approach to loosen regulatory constraints should focus attention on those constraints that actually bind when financial institutions are in trouble. My results suggest that in some cases reduced risk taking may be driven by forces other than capital requirements. Time varying capital requirements may therefore not be sufficient to improve credit supply. Actions that make financial institutions' future clear, such as stress tests, recapitalization, and perhaps even clear resolution frameworks, might be more effective. 


\section{References}

AAA (1999), Phase i report of the american academy of acrutaries' c-3 subgroup of the life risk based capital task force, Technical report, American Academy of Actuaries.

AAA (2014), Recommended approach for updating regulatory risk-based capital requirements for interest rate risk for fixed annuities and single premium life insurance, Technical report, American Academy of Actuaries.

Acharya, V. V. \& Viswanathan, S. (2011), 'Leverage, moral hazard, and liquidity', The Journal of Finance 66(1), 99-138.

Becker, B. \& Ivashina, V. (2015), 'Reaching for yield in the bond market', The Journal of Finance 70(5), 1863-1902.

Becker, B. \& Opp, M. M. (2014), 'Regulatory reform and risk-taking: Replacing ratings'.

Begenau, J., Piazzesi, M. \& Schneider, M. (2015), Banks' risk exposures, Working Paper 21334, National Bureau of Economic Research.

Berends, K. \& King, T. B. (2015), Derivatives and collateral at u.s. life insurers, Technical report.

Berends, K. R., McMenamin, R., Plestis, T. \& Rosen, R. J. (2013), 'The sensitivity of life insurance firms to interest rate changes'.

Bidder, R. M., Krainer, J. R. \& Shapiro, A. H. (2017), De-leveraging or de-risking? how banks cope with loss, Working Paper 2017-03, Federal Reserve Bank of San Francisco.

Brewer III, E., Mondschean, T. H. \& Strahan, P. E. (1993), 'Why the life insurance industry did not face an "s\&l-type" crisis', Economic Perspectives 17(5), 12-24.

Briys, E. \& De Varenne, F. (1997), 'On the risk of insurance liabilities: debunking some common pitfalls', Journal of Risk and Insurance pp. 673-694.

Brunnermeier, M. K. \& Sannikov, Y. (2014), 'A macroeconomic model with a financial sector', The American Economic Review 104(2), 379-421.

Chodorow-Reich, G. (2014), 'Effects of unconventional monetary policy on financial institutions', Brookings Papers on Economic Activity p. 155.

Chodorow-Reich, G., Ghent, A. \& Haddad, V. (2016), 'Asset insulators'.

Coimbra, N. \& Rey, H. (2017), Financial cycles with heterogeneous intermediaries, Working Paper 23245, National Bureau of Economic Research.

Cooper, E., Andre, A., Gabovich, S. \& Pomerantz, A. (2010), Revisiting the role of insurance company alm within a risk management framework, Technical report, Goldman Sachs Asset Management.

Coval, J., Jurek, J. \& Stafford, E. (2009), 'The economics of structured finance', The Journal of Economic Perspectives 23(1), 3-25. 
Dagher, J. C., Dell'Ariccia, G., Laeven, L., Ratnovski, L. \& Tong, H. (2016), Benefits and costs of bank capital, Staff Discussion Note 16/04, International Monetary Fund.

DeAngelo, H., DeAngelo, L. \& Gilson, S. C. (1994), 'The collapse of first executive corporation junk bonds, adverse publicity, and the run on the bank phenomenon', Journal of Financial Economics 36(3), 287-336.

Dell'Ariccia, G., Laeven, L. \& Suarez, G. (2016), 'Bank leverage and monetary policy's risk-taking channel: Evidence from the united states'.

Domanski, D., Shin, H. S. \& Sushko, V. (2015), 'The hunt for duration: not waving but drowning?', (519).

Drechsler, I., Drechsel, T., Marques-Ibanez, D. \& Schnabl, P. (2016), 'Who borrows from the lender of last resort?', The Journal of Finance 71(5), 1933-1974.

Eber, M. (2016), 'Taking risk when rates are low? evidence from life insurance'.

EIOPA (2014), EIOPA Insurance stress test 2014.

Ellul, A., Jotikasthira, C., Lundblad, C. T. \& Wang, Y. (2015), 'Is historical cost accounting a panacea? market stress, incentive distortions, and gains trading', The Journal of Finance 70(6), 2489-2538.

Esty, B. C. (1998), 'The impact of contingent liability on commercial bank risk taking', Journal of Financial Economics 47(2), 189 - 218.

Fama, E. F. \& French, K. R. (1997), 'Industry costs of equity', Journal of Financial Economics 43(2), 153-193.

FIO (2013), How to Modernize and Improve the System of Insurance Regulation in the United States, Federal Insurance Office, U.S. Department of the Treasury.

Foley-Fisher, N., Narajabad, B. \& Verani, S. (2015), 'Self-fulfilling runs: evidence from the us life insurance industry'.

Foley-Fisher, N., Narajabad, B. \& Verani, S. (2016), Securities lending as wholesale funding: Evidence from the u.s. life insurance industry, Working Paper 22774, National Bureau of Economic Research.

Gertler, M. \& Karadi, P. (2011), 'A model of unconventional monetary policy', Journal of monetary Economics 58(1), 17-34.

Gertler, M. \& Kiyotaki, N. (2010), 'Financial intermediation and credit policy in business cycle analysis', Handbook of monetary economics 3(3), 547-599.

Gilje, E. P. (2016), 'Do firms engage in risk-shifting? empirical evidence', The Review of Financial Studies 29(11), 2925.

Greenstone, M., Mas, A. \& Nguyen, H.-L. (2014), Do credit market shocks affect the real economy? quasi-experimental evidence from the great recession and 'normal' economic times, Technical report, National Bureau of Economic Research. 
Hanson, S. G., Kashyap, A. K. \& Stein, J. C. (2011), 'A macroprudential approach to financial regulation', The Journal of Economic Perspectives 25(1), 3-28.

Hanson, S. G., Shleifer, A., Stein, J. C. \& Vishny, R. W. (2015), 'Banks as patient fixed-income investors', Journal of Financial Economics 117(3), 449-469.

Hartley, D., Paulson, A. \& Rosen, R. J. (2016), 'Measuring interest rate risk in the life insurance sector', The Economics, Regulation, and Systemic Risk of Insurance Markets p. 124.

He, Z. \& Krishnamurthy, A. (2013), 'Intermediary asset pricing', The American Economic Review 103(2), 732-770.

Hellmann, T. F., Murdock, K. C. \& Stiglitz, J. E. (2000), 'Liberalization, moral hazard in banking, and prudential regulation: Are capital requirements enough?', The American Economic Review 90(1), 147-165.

Holsboer, J. H. (2000), 'The impact of low interest rates on insurers', The Geneva Papers on Risk and Insurance. Issues and Practice 25(1), 38-58.

IMF (2016), The Insurance Sector - Trends and Systemic Risk Implications.

Jensen, M. C. \& Meckling, W. H. (1976), 'Theory of the firm: Managerial behavior, agency costs and ownership structure', Journal of Financial Economics 3(4), 305-360.

Keeley, M. C. (1990), 'Deposit insurance, risk, and market power in banking', The American Economic Review 80(5), 1183-1200.

Khwaja, A. I. \& Mian, A. (2008), 'Tracing the impact of bank liquidity shocks: Evidence from an emerging market', The American Economic Review 98(4), 1413-1442.

Kirti, D. (2017), Why do bank-dependent firms bear interest-rate risk?, Working Paper 17/03, International Monetary Fund.

Koijen, R. S. \& Yogo, M. (2015a), 'The cost of financial frictions for life insurers', American Economic Review 105(1), 445-75.

Koijen, R. S. \& Yogo, M. (2015b), 'Risks of life insurers: Recent trends and transmission mechanisms'.

Koijen, R. S. \& Yogo, M. (2016), 'Shadow insurance', Econometrica 84(3), 1265-1287.

Maggiori, M. (2016), 'Financial intermediation, international risk sharing, and reserve currencies'.

Marcus, A. J. (1984), 'Deregulation and bank financial policy', Journal of Banking Finance 8(4), $557-565$.

Matutes, C. \& Vives, X. (2000), 'Imperfect competition, risk taking, and regulation in banking', European Economic Review 44(1), 1 - 34.

McDonald, R. \& Paulson, A. (2015), 'Aig in hindsight', The Journal of Economic Perspectives 29(2), 81-105. 
Merrill, C. B., Nadauld, T. D., Stulz, R. M. \& Sherlund, S. (2012), Did capital requirements and fair value accounting spark fire sales in distressed mortgage-backed securities?, Technical report, National Bureau of Economic Research.

Merrill, C. B., Nadauld, T. \& Strahan, P. E. (2014), 'Final demand for structured finance securities'.

Mian, A. \& Sufi, A. (2010a), 'The great recession: Lessons from microeconomic data', The American Economic Review 100(2), 51-56.

Mian, A. \& Sufi, A. (2010b), 'Household leverage and the recession of 2007 - 09', IMF Economic Review 58(1), 74-117.

NAIC (2012), Risk-Based Capital (RBC) for Insurers Model Act.

NAIC (2013), The U.S. National State-Based System of Insurance Financial Regulation and the Solvency Modernization Initiative.

Plantin, G. \& Rochet, J.-C. (2007), When Insurers Go Bust: An Economic Analysis of the Role and Design of Prudential Regulation, Princeton University Press.

Plosser, M. C. \& Santos, J. A. (2014), 'Banks' incentives and the quality of internal risk models'.

Poterba, J. M. (1997), The history of annuities in the united states, Technical report, National Bureau of Economic Research.

Rajan, R. G. (2006), 'Has finance made the world riskier?', European Financial Management 12(4), 499-533.

Rampini, A. A., Viswanathan, S. \& Vuillemey, G. (2015), 'Risk management in financial institutions'.

Repullo, R. (2004), 'Capital requirements, market power, and risk-taking in banking', Journal of Financial Intermediation 13(2), 156 - 182.

Rochet, J.-C. (2008), Why Are There So Many Banking Crises?: The Politics and Policy of Bank Regulation, Princeton University Press.

Sarin, N. \& Summers, L. H. (2016), 'Have big banks gotten safer', Brookings Papers on Economic Activity pp. 15-16.

Seifert, C. A. (2014), Industry surveys insurance: Life \& health, Technical report, S\&P Capital IQ.

Stiglitz, J. E. \& Weiss, A. (1981), 'Credit rationing in markets with imperfect information', The American Economic Review 71(3), 393-410.

Thompson, S. B. (2011), 'Simple formulas for standard errors that cluster by both firm and time', Journal of Financial Economics 99(1), 1-10.

Zentefis, A. K. (2014), 'Risk-taking under a punishing bailout'. 


\section{A Data}

\section{A.1 Insurers}

I obtain insurance regulatory data from SNL Financial. The data is ultimately sourced from insurance regulatory filings submitted to the NAIC: bonds in the general account are reported on Schedule D, and derivatives are reported on Schedule DB. Aggregate data is also based on insurance regulatory filings (as opposed to SEC filings or annual reports). I also obtain data on bond and issuer characteristics from Mergent FISD and data on interest rates and swap rates from Bloomberg. I restrict attention to life insurance subsidiaries, and focus on bonds held in the general account. I obtain data from 2005-2014. Data includes quarterly holdings and daily transactions.

I aggregate the data up to the group level pro-forma based on current ownership relationships, as reported by SNL. I identify individual companies based on NAIC Company Codes, and groups based on NAIC Group Numbers. I retain insurers that are not part of any insurance group in the sample, and identify them based on NAIC Company Codes.

\section{A.1.1 General account bonds}

Data on holdings of bonds is reported on Schedule D - Part 1. I obtain data on all bonds held in the general account. SNL provides this data with an identifier (company investment key). Both the fair value and par value of bonds are reported, allowing prices to be calculated. The fair value is reported for each bond at the end of each year when held. For interim quarters, the fair value is a blended value, based on the fair value reported at the end of the previous year, and price paid for bonds bought and consideration received for bonds sold since the end of the previous year. I drop observations where the fair value is 0 , missing or negative, or where the par value is 0 . I calculate the price as the ratio of fair value scaled by par value, and drop observations where the price is outside of the interval $[0.5,2]$.

I match bonds to their owners (based on NAIC Company Code) and characteristics using the company investment key. Bond characteristics include CUSIP, asset type, issuer type, maturity, coupon, rate type (fixed or floating). I drop hybrid securities, or bonds with maturity date before 
the relevant quarter. If no rate type is reported, I assume the bond is fixed rate. I also collect NAIC categories, as reported in regulatory filings, in each quarter. I collect supplemental information on bond characteristics from Mergent FISD. Using the issuer's SIC code from Mergent FISD, I identify financial issuers based on their corresponding Fama \& French (1997) industry. I also obtain the bond offering date from Mergent FISD.

I calculate DV01 at the bond identifier level based on prices reported by each insurer by quarter. I round bond maturity in a given quarter (as of the reporting date at the end of the quarter) to the nearest half year. I drop observations with missing coupon information, or if the bond has 0 maturity and a fixed rate. I only calculate DV01 for fixed-rate bonds, and set it to 0 when the bond is explicitly categorized as floating rate, or reported exactly at par value. I calculate the yield to maturity of each bond observation numerically. The price of a bond with Maturity of $N$ years, coupon $C$, payment frequency $f$, and yield to maturity $Y$ is

$$
\begin{aligned}
P[N, C, f, Y] & =\sum_{i=1}^{f N} \frac{C / f}{(1+Y / f)^{i}}+\frac{1}{(1+Y / f)^{f N}} \\
& =(1+Y / f)^{-f N}+\frac{C}{Y}\left[1-(1+Y / f)^{-f N}\right] \\
& =\frac{C}{Y}+\frac{Y-C}{(1+Y / f)^{f N}}
\end{aligned}
$$

Assuming semi-annual payment $(f=2)$, I use a bisection search to calculate the yield to maturity (all information other than the YTM is available). I run 20 iterations of a bisection search, and use the final midpoint as the yield to maturity. I match the estimated price of the bond using the calculated yield to maturity to the reported fair value, and drop the observation if the reported fair value is not within $1 \%$ of the estimated fair value. I then calculate DV01 numerically as the difference in price given a $1 \%$ shift in yield to maturity. I also calculate duration, assuming annual coupon payments.

I classify bonds into separate asset classes. I identify bonds as corporate bonds when the issuer is reported by SNL as either an industrial or utility company, where the issuer is not in the Fama \& French (1997) finance industry, and the bond is not a structured bond. I identify government bonds as bonds issued by the US Federal government, a government agency, US states, local governments 
or foreign governments, excluding any structured bonds. I identify bonds issued by financial firms (in the Fama \& French (1997) finance industry) excluding structured bonds. Private structured bonds are bonds issued by an industrial or utility issuer and are structured (this includes RMBS, CMBS, MBS, ABS and other structured bonds). Agency bonds are structured bonds issued by any type of government issuer.

\section{A.1.2 Derivatives oustanding}

I collect data on interest-rate derivatives for 2005-2014 on a quarterly basis, and filter for standard single-currency interest-rate swaps. Reporting requirements for derivatives changed in 2010, but swaps were consistently reported. Prior to 2010, this data was reported on Schedule DB - Part C Section 1 (all collars, swaps and forwards open as of reporting date). After 2010, this data was reported on Schedule DB - Part A Section 1 (all options, caps, floors, collars, swaps and forwards open as of reporting date). Variables include NAIC Company code, a text description, information on the terms or strike (also a text field), the notional amount and fair value. Data is at the transaction level. Initiation and maturity dates are also reported for all transactions.

I filter derivatives to retain only observations likely to pertain to standard single-currency interest-rate swaps. I use row numbers to perform an initial screen to do so. I drop observations when row numbers are not in ranges corresponding to a designated interest-rate swap type. Prior to 2010, this includes hedging (500000-599999) and other (700000-799999). After 2010, this includes hedging effective (850000-859999), hedging other (910000-919999), replication (970000-979999), income generation (1030000-1039999) and other (1090000-1099999). After 2010, risk type is also reported, and I only keep observations for which the risk type matches interest-rate risk. Using information in the description and strike fields, I exclude transactions that are likely to refer to CDS, currency swaps, total return swaps, inflation swaps or other miscellaneous swaps. I also drop observations where initiation or maturity are not reported. For some insurers, the two legs

of swaps are reported as separate line items. I match these legs based on row numbers and terms (counterparty, notional, initiation and maturity) and combine them.

I parse the direction and fixed rate on the fixed leg of the swap from text fields describing the 
transaction and terms (description and strike). For some firms (e.g. Metlife), the terms of the swap are clearer in the description than in the strike. Some swaps also have an adjustment on the floating leg (e.g. LIBOR + 50bps). I subtract the index adjustment from the fixed leg and treat the swap as otherwise standard. I merge in data on LIBOR and the maturity appropriate swap rate (both from Bloomberg) for both the initiation and the reporting date. I log-linearly interpolate the swap curve using the largest subset of maturities available from the set $\{2,3,5,7,10,20,30\}$. This allows me to determine the likely sign of the fair value, as of the reporting date, of a fixed-rate swap initiated on the initiation date. I then proceed to identify the direction and fixed rate as follows:

1. In the best case, the direction of the swap (e.g. receive fixed, pay LIBOR) is identified clearly, and two separate interest rates can be identified from information on the strike. Before categorizing swaps as this type, I check whether the sign of the swap fair value matches what would be expected given general market rates, unless the fixed rate of the swap was more than $1 \%$ different from the swap rate at initiation, or the direction is very clearly reported.

2. In the next case, the direction is identified clearly, but only a single rate can be identified from information on swap terms. Before using the single rate as the fixed rate, I check whether it is closer to LIBOR as of the reporting date than the swap rate at initiation. Before categorizing swaps as this type, I check whether the sign of the swap fair value matches what would be expected given general market rates, unless the fixed rate of the swap was more than $1 \%$ different from the swap rate at initiation, or the direction is very clearly reported.

3. When information on the direction is available, but no information is available on the rate, I use the swap curve at initiation to determine the fixed rate.

4. When two rates are not available and the swap is not matched to this point, I identify the direction from the sign of the swap's fair value in combination with changes in market conditions, and the fixed rate from the swap curve at initiation.

5. When two rates are available (in formats designating which rate is paid and which is received) and the swap is not matched to this point, I check which rate is closer to LIBOR at the reporting date and which leg is closer to the swap curve at initiation. 
The table below shows that the majority of swaps are classified based on the first step, but that the remaining steps are important. Reporting is less clear for certain firms (e.g. Prudential and Aegon), making it more likely that their swaps are classified in later steps.

\begin{tabular}{|c|c|}
\hline Type & \# of swaps (000's) \\
\hline 1 & 399 \\
\hline 2 & 11 \\
\hline 3 & 17 \\
\hline 4 & 21 \\
\hline 5 & 0.2 \\
\hline Total & 448 \\
\hline
\end{tabular}

Having identified the direction and fixed rate on the fixed leg of the swap, I proceed to price it and calculate DV01. The fair value of a pay-fixed (receive-floating) swap is

$$
\text { Notional } \times(1-P[N, C, f, Y])
$$

as the floating leg is always valued at par, where the price of the bond is defined by Equation 1 . The price of a pay-floating swap is this value multiplied by -1. I use the log-linearly interpolated swap curve as of the reporting date as the yield to price swaps, and assume semi-annual payment of coupons. Finally, I calculate DV01 numerically as the change in fair value given a one basis point shift in the swap curve.

\section{A.1.3 Bond and derivatives transactions}

Data is also available to construct a view of bond transactions on a daily level for bonds in the general account. Bond acquisitions are reported on Schedule D - Part 3, and disposals are reported on Schedule D - Part 4, all providing transaction dates. Data is reported on the purchase price for acquisitions and consideration received for disposals, as well as par value. Entity identifiers (NAIC Company Code) and bond CUSIP are also reported. I collect this data for 2005-2014. I match transaction level information to bond characteristics as reported by SNL at the NAIC Company 
Code and CUSIP level.

I calculate yield to maturity and DV01 numerically as before, using the reported transaction price (or consideration received) scaled by par value. I treat transactions reported exactly at par separately (and assume only the par value is reported correctly). For these, I match to the DV01 per unit of par value from the quarterly view for the previous quarter, matching NAIC Company Code and CUSIP. If the bond does not match in the previous quarter, I match to the current quarter (as the bond may have been purchased for the first time that quarter).

I use transaction data to calculate weighted yield to maturity of all bonds purchased, by insurerquarter, to measure credit risk. To do so, I take the weighted average (weighting by fair value) of all purchases in the quarter, by NAIC Group. I exclude bonds reported exactly at par from this calculation. Therefore, I use only prices reported on the day of the transaction, in the relevant quarter.

For bond level analysis, I focus on newly issued bonds. I identify newly issued bonds using issuance data from Dealogic. I start with tranche level data on all USD, fixed rate, corporate and private MBS bonds issued from 2005-2014, excluding money market securities. I match this issuance data to daily transaction level data via CUSIPs. Within the transaction data, I find the first transaction date for a given CUSIP (for all life insurers, not just large insurers). I restrict regressions to bonds where the first transaction is within two weeks of the Dealogic deal pricing date (the vast majority of bonds match exactly). I calculate the fair value value weighted yield to maturity for all transactions by life insurers within three months of the first transaction date (for regressions I winsorize this variable at the 5th and 95th percentile by NAIC category). I also calculate the fraction of net purchases within three months of the first transaction date by insurers hit hard, as a fraction of net purchases within three months of the first transaction date by all large insurers with matched parents (for regressions I winsorize this variable at the 5th and 95th percentile by NAIC category). I restrict regressions to bonds with at least ten transactions within this window by large insurers with matched parents. Regressions include month dummies based on the first transaction date, and issuer dummies based on Dealogic's issuer classification (Issuer short code). 
I identify passive sales (regular repayments likely to be prepayments, paydowns or amortization). As MBS paydowns happen regularly on the 1st of December of each year as well as (to a lesser degree) the 1st of the last month of other quarters, I classify any sales of structured bonds on these dates as paydowns. I also identify regular cycles of frequent sales for other kinds of bonds. To do so, I first find the mode sale month (e.g. December) and the mode sale day (e.g. 15th). Then, if sales within one day (14th-16th) in an annual, semi-annual or quarterly cycle account for half of the number of sales, and more than 50 sales are reported for the CUSIP, I identify sales fitting the pattern as passive sales.

Data is also available to construct a view of daily trading in derivatives. All derivatives positions reported open at the end of each reporting period provide initiation dates, as discussed above. All transactions terminated within a year are reported separately, which allow terminations as well as transactions only held within a quarter to be identified. Prior to 2010, this data was reported on Schedule DB - Part C Section 3 (all collars, swaps and forwards terminated during current year). After 2010, this data was reported on Schedule DB - Part A Section 2 (all options, caps, floors, collars, swaps and forwards terminated during current year). I use quarterly data for initiations when possible. I proceed to find changes in DV01 resulting from transactions as above. 


\section{A.2 Banks}

Data on banks at the holding company level is from form FR-Y9C, for 2005Q1-2014Q4. I obtain this data from the Chicago Federal Reserves website. I aggregate data pro-forma to present ownership using data on bank holding company mergers, also provided by the Chicago Federal Reserve. I match banks to present ownership and check for chains of mergers or acquisitions as in Kirti (2017). I restrict the sample to banks with at least $\$ 10 \mathrm{BN}$ in assets as of 2014Q4. I obtain call report data at the commercial bank level for 2001Q1-2014Q4 from the FFIEC's website. I aggregate call report data to the parent holding company level on a pro-forma basis using current ownership, as reported by SNL.

I use loan growth measures for different types of loans, based on data at the holding company level: all are changes in natural logarithms. Real estate loans are bhck1410 (loans secured by real estate), reported on Schedule HC-C. Allowances for loan and lease losses are not deducted on Schedule HC-C. Total loans the sum of bhckb529 (loans and leases, net of unearned income and allowance for loan and lease losses) and bhck5369 (loans and leases held for sale), reported on Schedule HC. This definition of loans does deduct the allowance for loan and lease losses. Non real estate loans are total loans minus real estate loans, where total loans are inflated by the total allowance for loan and lease losses (bhck3123). Both real estate loan growth and non-real estate loan growth are therefore before loan and lease losses are deducted, while total loan growth is after loan and lease losses are deducted.

The fraction of loans with maturity greater than one year is based on call report data at the commercial bank level. This refers to the fraction of loans with reported breakdowns where the remaining maturity or next repricing date is more than one year. This data is reported on Schedule RC-C Part I: rcona564-rcona569 and rcfda570-rcfda575. 


\section{B Figures}

Figure 1: Composition of assets for US life insurers and banks (2014)

Notes: This figure shows the composition of assets for US life insurers and banks, using aggregate Flow of Funds data as of 2014. Banks are US chartered depository institutions. Bonds are debt securities in the flow of funds classification. For insurers, equity held in separate accounts is shown separately. The largest category encompassed within 'other' assets for banks is reserves held at the Federal Reserve. All values are in trillions of dollars.

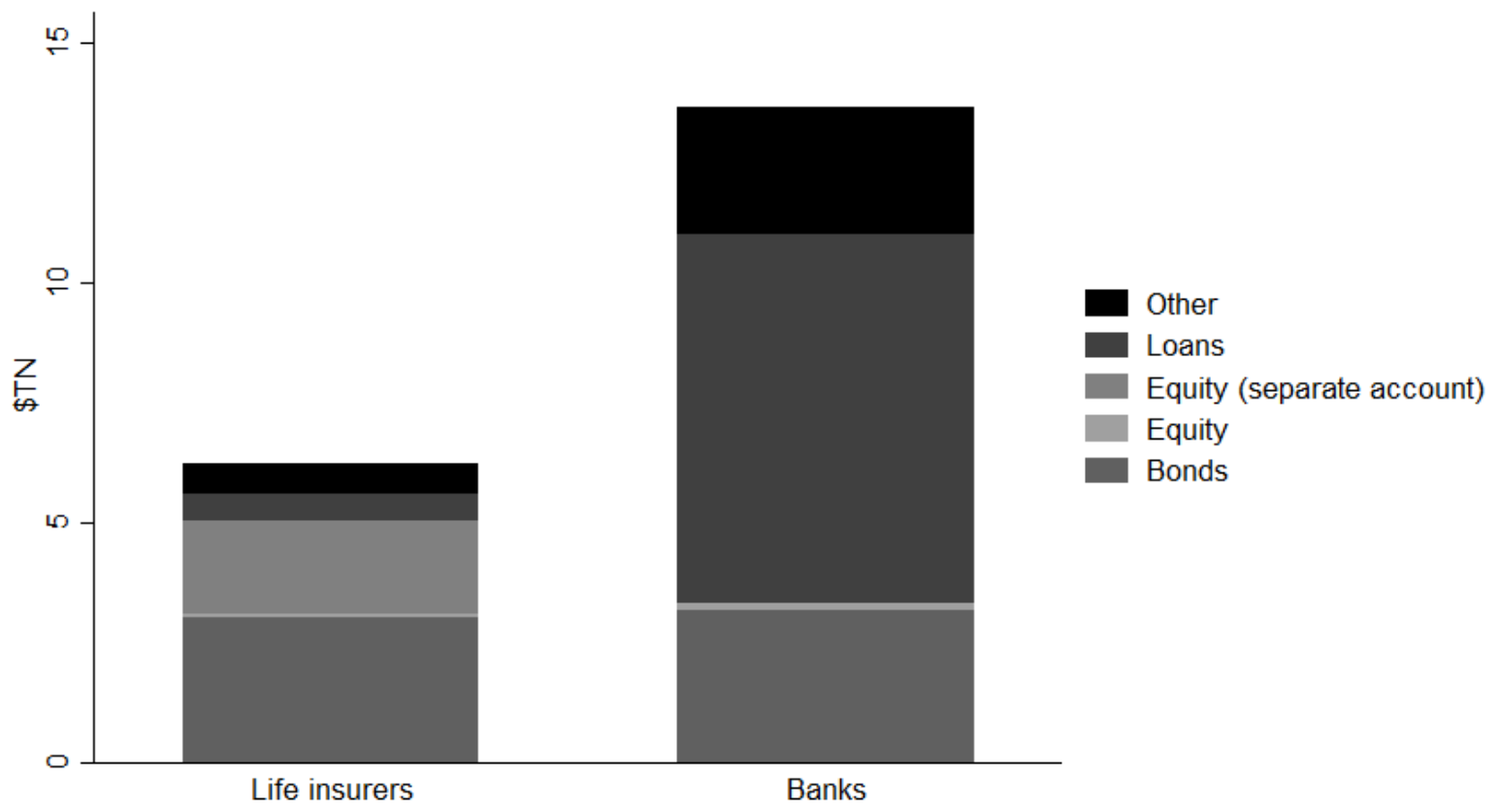


Figure 2: Net DV01 gap for large insurers with matched parents

Notes: This figure shows the composition of the DV01 gap for large US insurers with matched corporate parents. The data is quarterly, from 2005Q1-2014Q4. Bond DV01, Derivatives DV01 and the gap to Liability DV01 are shown stacked (all in \$BN). Bond and derivatives DV01 are shown scaled as positive even though they are negative numbers. The total height of the bars in each quarter is the total Liability DV01. I calculate Bond and derivatives DV01 based on detailed position level data. I estimate liability DV01 assuming a constant modified duration of 15 years. See Section 3 for details.

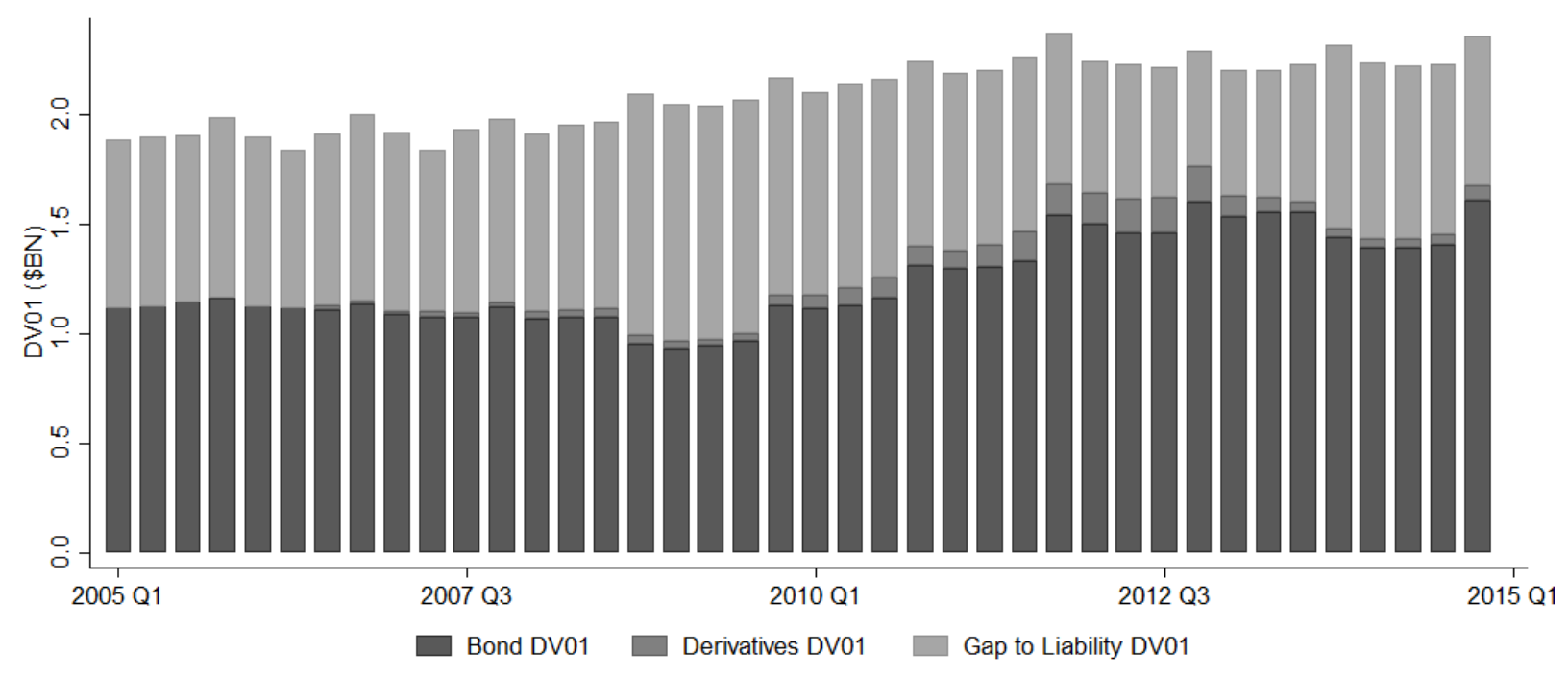


Figure 3: Insurers' interest-rate swaps: total, net receive fixed, and duration-equivalent notional

Notes: This figure shows measures of the size of interest-rate swap portfolios (in $\$ \mathrm{BN}$ ) held by large US life insurers with matched parents for 2010Q2, 2012Q2 and 2014Q4. In each quarter, the figure first shows total notional amounts separated by whether the swaps are pay-fixed or receivefixed. Next the figure shows the net receive-fixed notional amount. Finally, the figure shows the duration-equivalent notional. This is the amount of bonds that insurers would need to hold (with the same duration as their bond portfolio) to obtain equivalent duration exposure. See Section 3 for details.

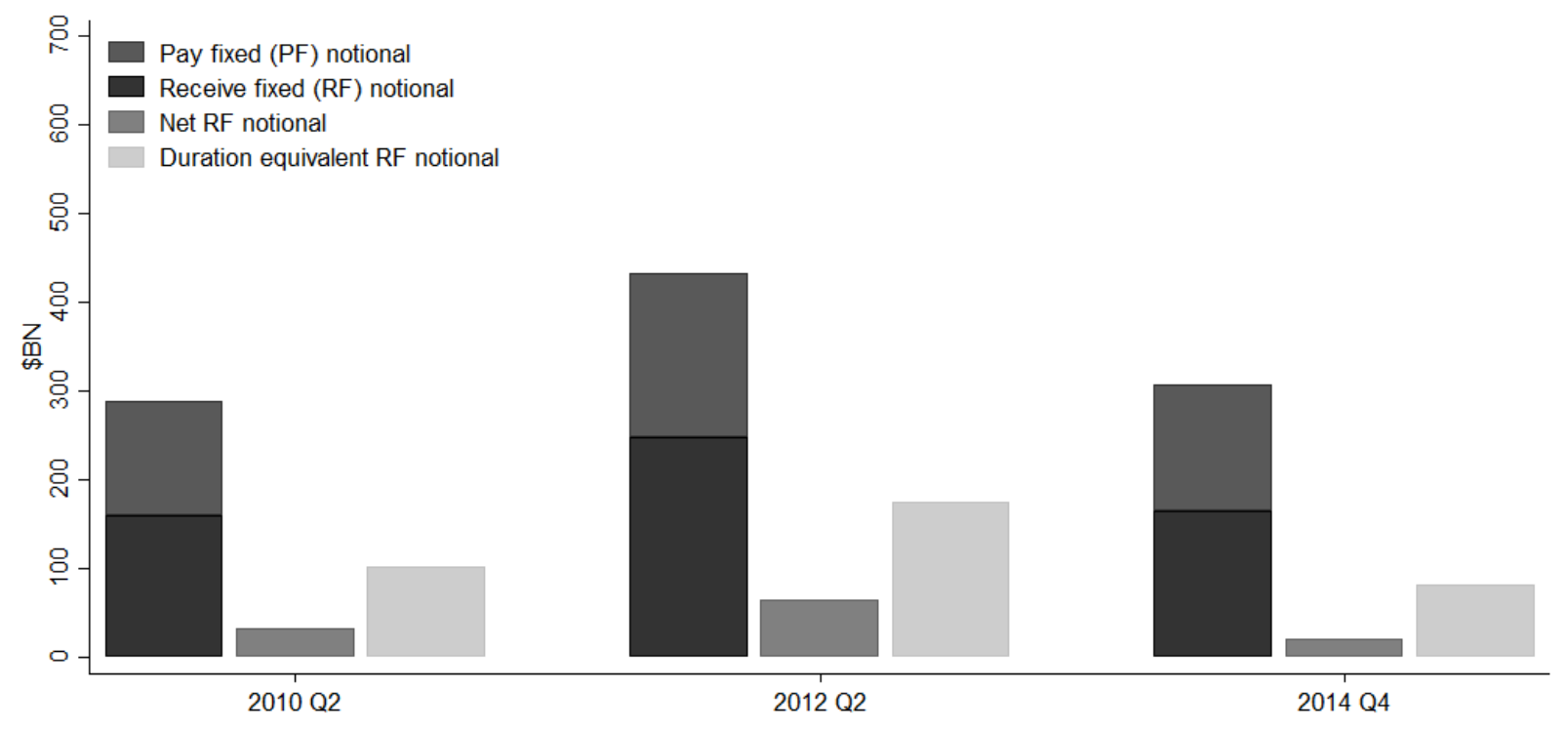


Figure 4: Risk taking based on crisis experience for large insurers with matched parent

Notes: This figure shows risk taking by insurers separated out by whether I categorize them as hit hard by the crisis. The data is quarterly, from 2005Q1-2014Q4. Panel A looks at interest-rate risk (Net DV01 Gap, in percentage points). Panel B looks at credit risk (average YTM on bonds purchased, in percentage points). In both cases, the panels show raw averages within categories of insurers. Cutoffs between the pre-crisis and crisis period (2007Q2) and crisis and post-crisis period (2010Q4) are marked.

\section{Panel A: Interest-rate risk}

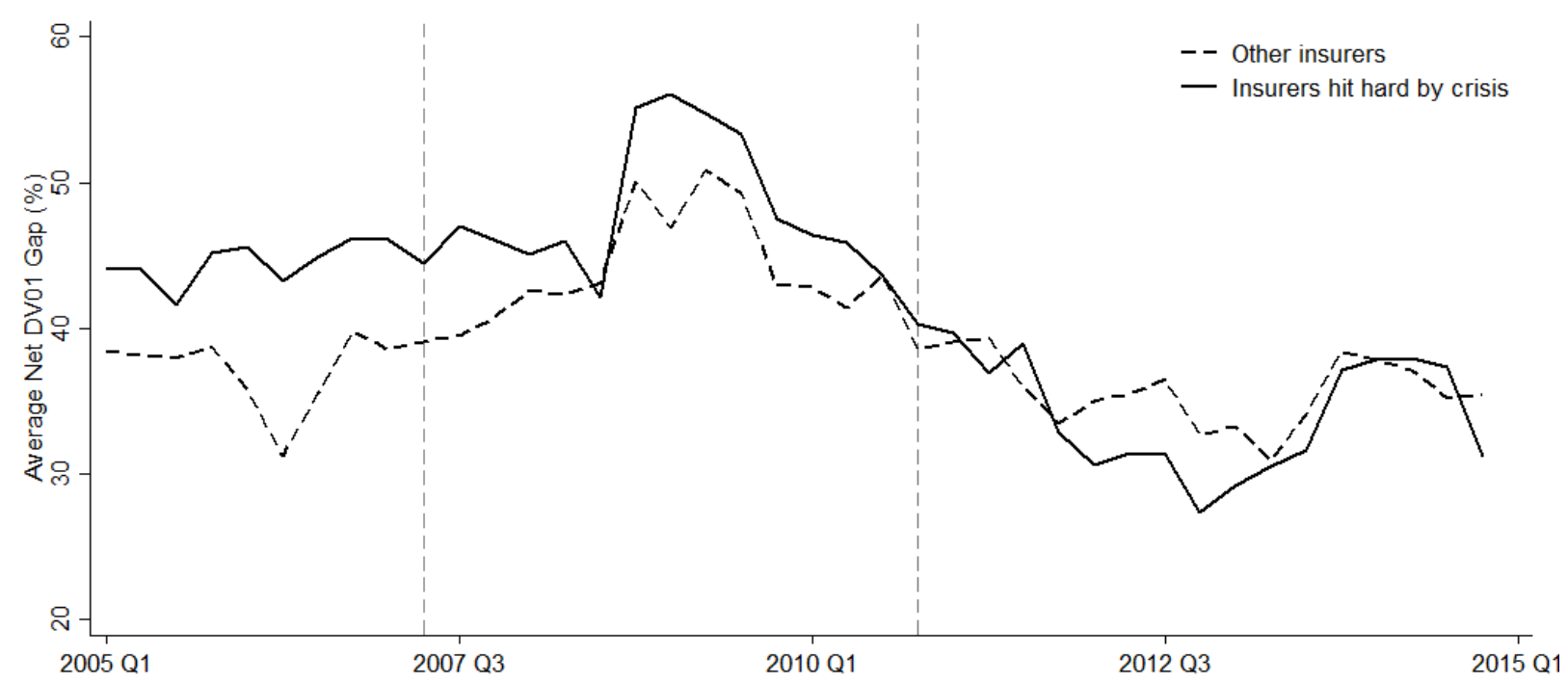

Panel B: Credit risk

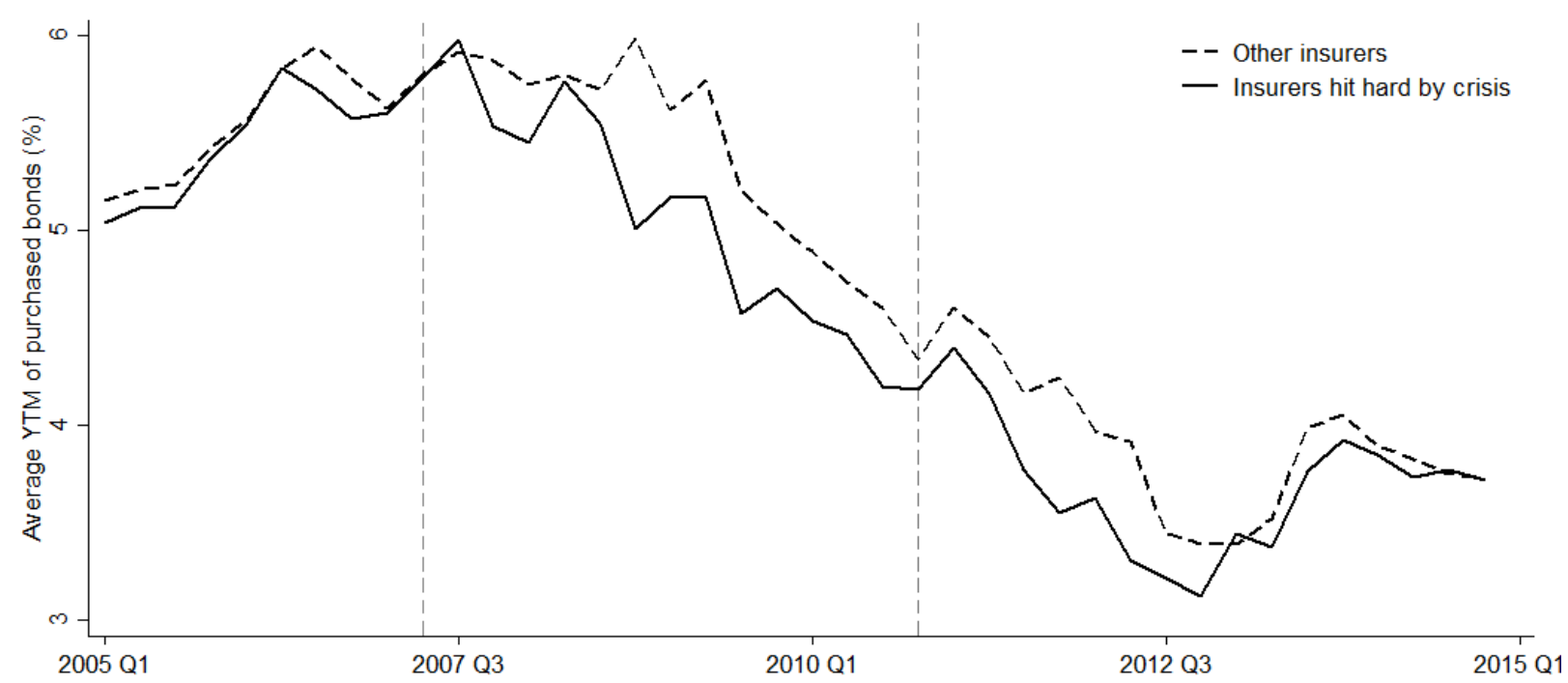


Figure 5: Net MBS purchases as a fraction of total net purchases from 2005-2014

Notes: This figure shows insurers' purchases of MBS using daily transaction level data from 20052014. Purchases are shown as cumulative net purchases (based on reported fair values), as a fraction of total net purchases over the full sample period, value weighted and in percentage points. Prepayments are excluded. Privately issued structured bonds, including all private MBS, and Agency MBS are shown separately. Panel A shows this for insurers hit hard by the crisis, and Panel B for insurers hit less hard by the crisis.

Panel A: Insurers hit hard by the crisis

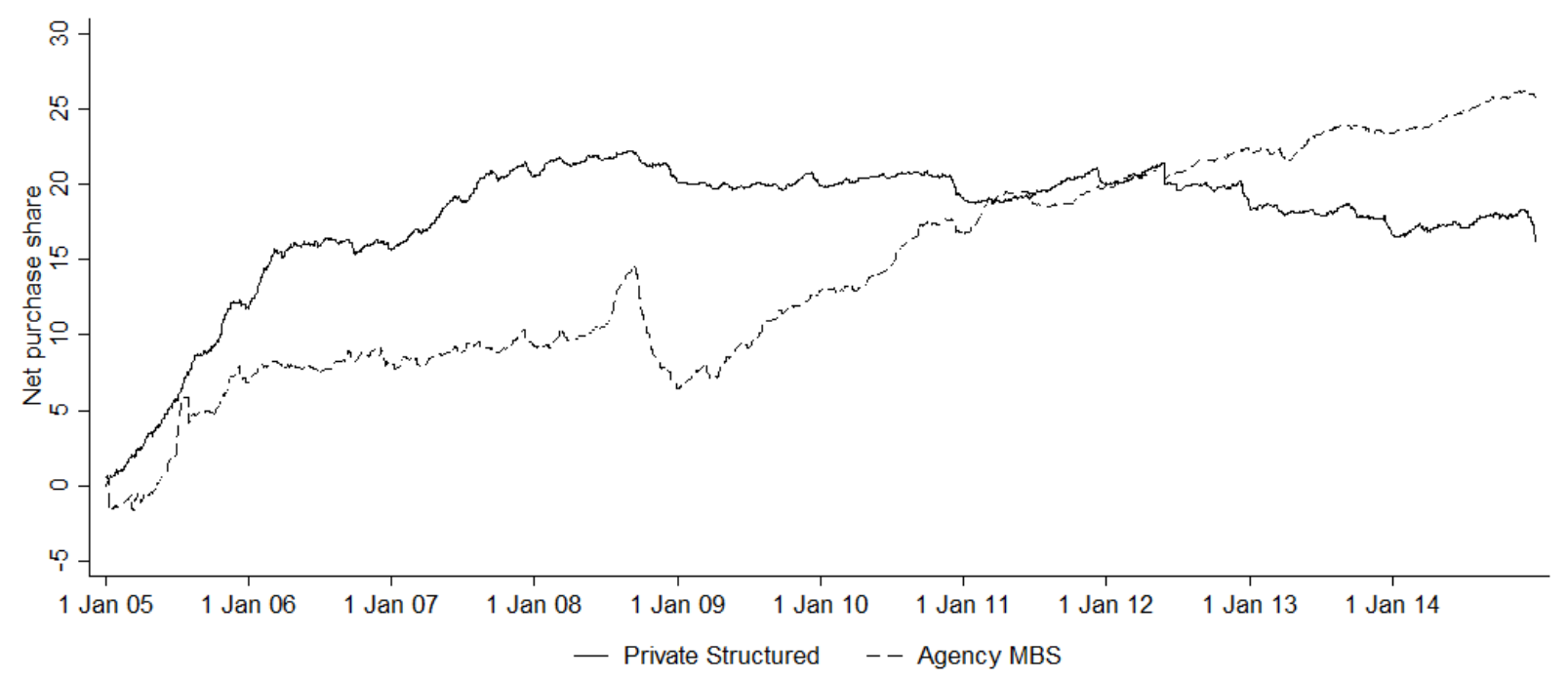

Panel B: Insurers hit less hard by the crisis

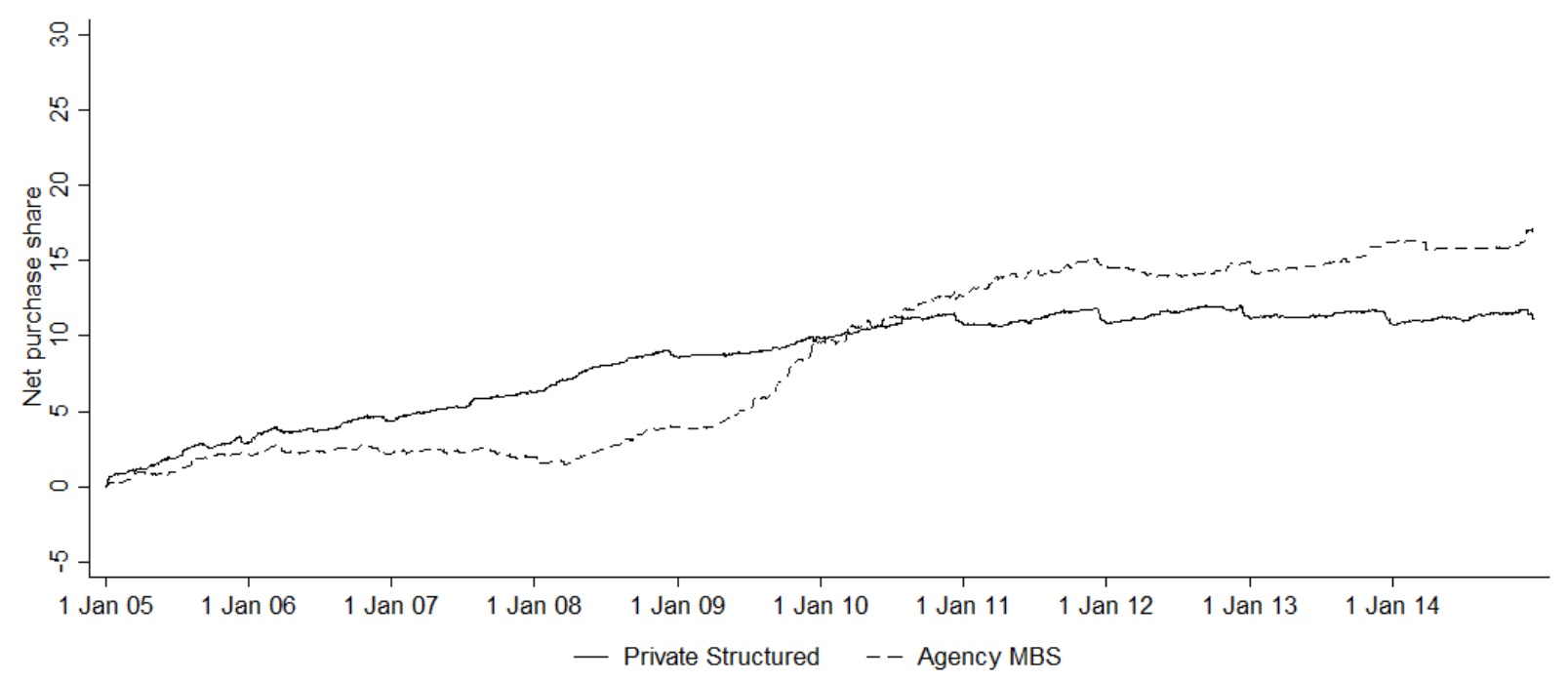


Figure 6: Private structured bonds bought by insurers hit hard in 2005 by rating

Notes: This figure shows the rating distribution of privately issued structured structured bonds bought in 2005 by insurers that ended up being hit hard by the crisis. Ratings are based on NAIC categories reported in insurance regulatory data. Ratings are shown at two points in time: as of the end of 2005, and as of the end of 2009. For both, weights, in percentage points, are based on net purchase shares in 2005. The safest category, NAIC 1, is omitted, but can be inferred from the sum of the bars for either 2005 or 2009.

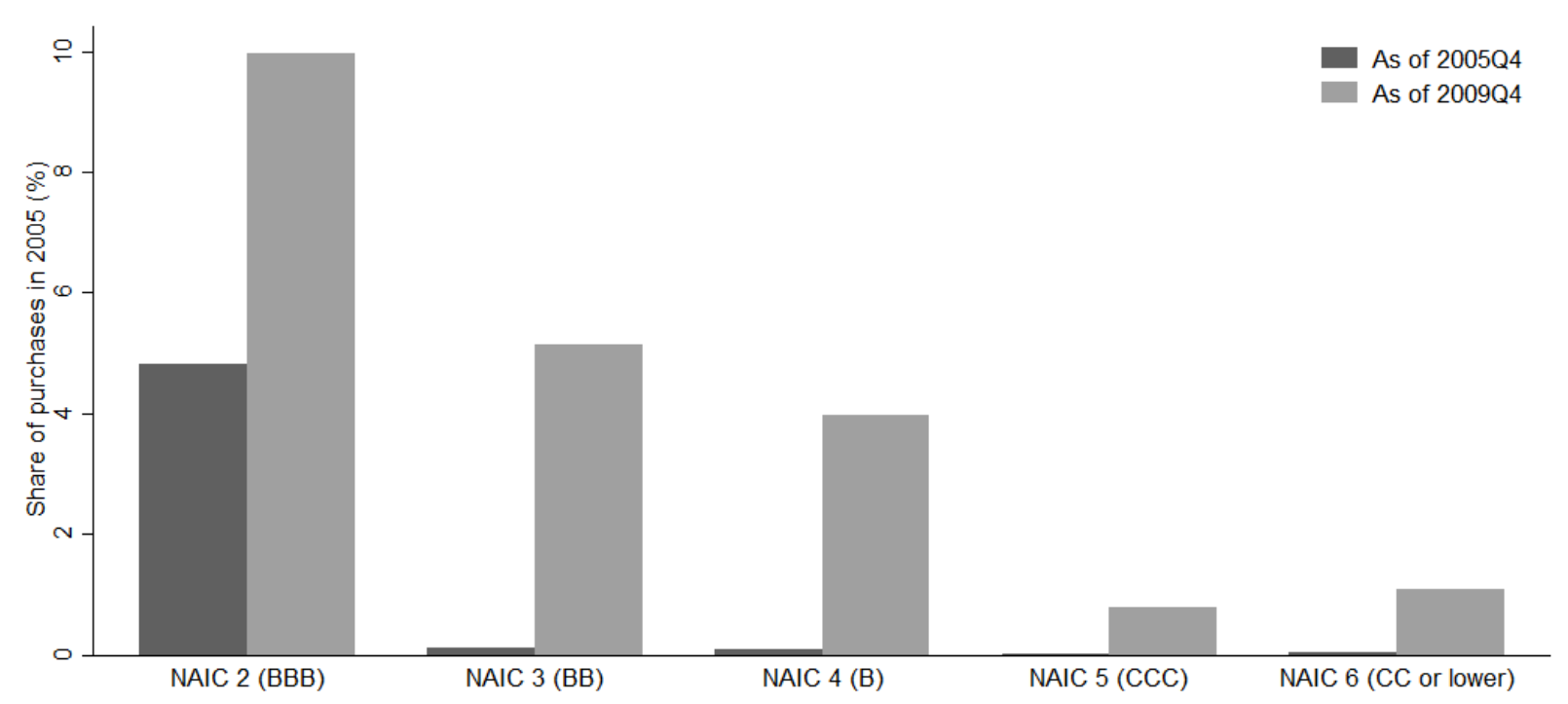


Figure 7: Risk taking based on crisis experience for large banks with matched parent

Notes: This figure shows risk taking by banks separated out by whether I categorize them as hit hard by the crisis. The data is quarterly, from 2005Q1-2014Q4. Panel A looks at interest-rate risk (fraction of loans maturing or repricing in more than one year, in percentage points). Panel B looks at credit risk (log changes in real estate loans, multiplied by 100). In both cases, the panels show raw averages within categories of banks. Cutoffs between the pre-crisis and crisis period (2007Q2) and crisis and post-crisis period (2010Q4) are marked.

Panel A: Interest-rate risk

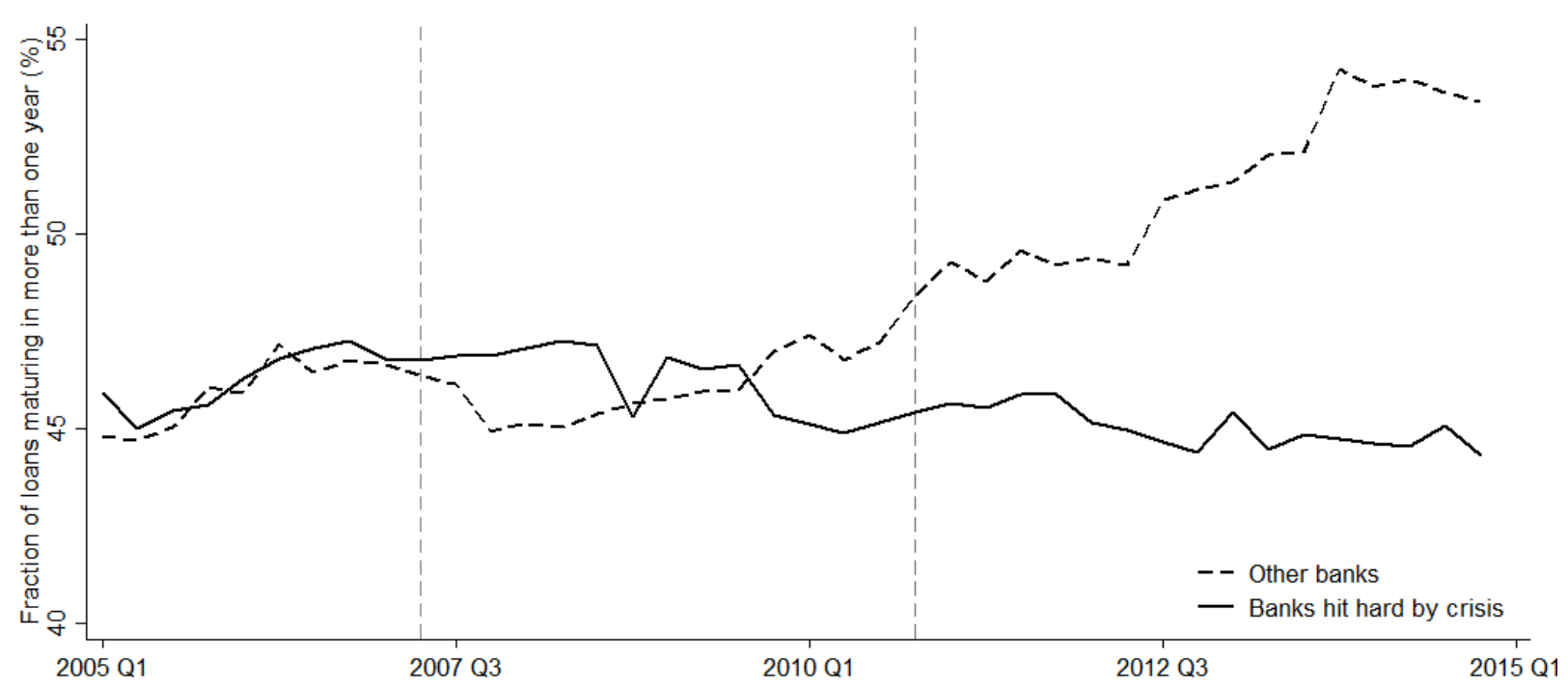

Panel B: Credit risk

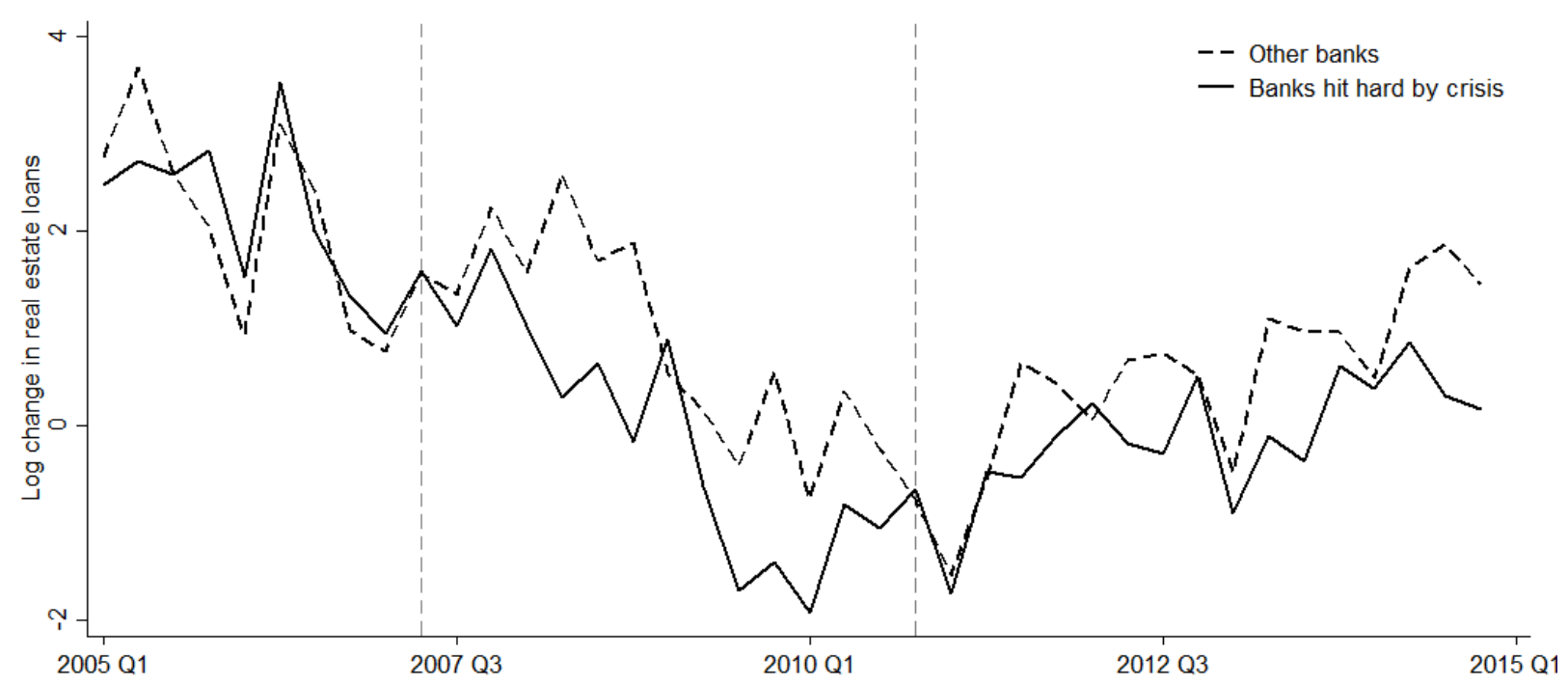




\section{Tables}

Table 1: Summary statistics for large insurers with matched parent

Notes: This table shows summary statistics of key variables for my sample of large US life insurers with matched corporate parents, separated by whether I categorize them as hit hard by the crisis or not. The data is quarterly, from 2005Q1-2014Q4. I aggregate the data to the insurance group level, pro-forma based on current ownership structures. Assets are reported in \$BN. Equity/Assets is surplus reported in regulatory filings scaled by assets, in percentage points and winsorized at the 5th and 95th percentiles. Bond DV01 Gap is (Liability DV01 -Bond DV01)/(Liability DV01), in percentage points with a cap at 100 and floor at 0. Net DV01 Gap is (Liability DV01 - Bond DV01 - Derivatives DV01)/(Liability DV01), in percentage points with a cap at 100 and floor at 0. YTM (Purchases) is the fair value value weighted average yield to maturity of all bonds purchased in the insurer-quarter, in basis points, winsorized at the 5th and 95th percentiles. Dur (Purchases) is the fair value value weighted average duration of all bonds purchased in the insurer-quarter, in years, winsorized at the 5 th and 95 th percentiles. The first column shows the mean for each variable in the full sample. The second column shows the mean excluding insurers hit hard by the crisis. 'Hit hard' is an insurer-level dummy for severe dividend cuts, reduction in equity/assets ratio or equity issuance during the crisis period, as described in Section 3. The third column shows the mean for insurers hit hard by the crisis. The final column shows the standard deviation in the full sample.

\begin{tabular}{lrrrr}
\hline & Full Sample & Others & Hit hard & Std. Dev. \\
\hline Assets (BN) & 92.3 & 38.6 & 135.8 & 113.7 \\
Equity/Assets & 8.0 & 9.6 & 6.8 & 4.8 \\
Bond DV01 Gap & 42.1 & 39.2 & 44.5 & 20.5 \\
Net DV01 Gap & 40.3 & 39.0 & 41.4 & 20.9 \\
YTM (Purchases) & 470.9 & 484.7 & 459.7 & 112.7 \\
Dur (Purchases) & 10.0 & 9.6 & 10.3 & 2.1 \\
\hline Insurer-Quarters & 1,701 & & & \\
Insurers & 50 & & & \\
\hline
\end{tabular}


Table 2: Risk taking based on crisis experience for large insurers with matched parent

Notes: This table shows regressions of Net DV01 Gap (interest-rate risk) and YTM (credit risk) on crisis experience for large insurers with matched parents. The data is quarterly, from 2005Q12014Q4. I aggregate the data to the insurance group level, pro-forma based on current ownership structures. Net DV01 Gap is (Liability DV01 - Bond DV01 - Derivatives DV01)/(Liability DV01), in percentage points with a cap at 100 and floor at 0 . YTM is the fair value value weighted average yield to maturity of all bonds purchased in the insurer-quarter, in basis points, winsorized at the 5th and 95th percentiles. Crisis Hit Flag is an insurer-level dummy for severe dividend cuts, reduction in equity/assets ratio or equity issuance during the crisis period, as described in Section 3. All specifications include interactions of Crisis Hit Flag with dummies for the crisis (2007Q3-2010Q4) and post-crisis (2011Q1-2014Q4) periods. All specifications include Log(Assets), the natural logarithm of total assets, as a control for size. Standard errors are double-clustered by insurer and quarter. $t$-statistics are shown in parentheses.

\begin{tabular}{lccrrrr}
\hline & \multicolumn{2}{c}{ Interest-rate risk } & & \multicolumn{2}{c}{ Credit risk } \\
\cline { 2 - 3 } \cline { 5 - 6 } & Net DV01 Gap & Net DV01 Gap & & YTM & YTM \\
\hline Crisis Hit Flag & 6.85 & & & & 13.64 & \\
& $(1.06)$ & & & $(1.15)$ & \\
Crisis Hit Flag $\times$ 2007Q3-2010Q4 & -3.22 & -2.94 & & -28.28 & -29.00 \\
& $(-2.63)$ & $(-1.26)$ & & $(-2.45)$ & $(-2.40)$ \\
Crisis Hit Flag $\times 2011 \mathrm{Q} 1-2014 \mathrm{Q} 4$ & -8.96 & -8.07 & & -16.19 & -14.29 \\
& $(-2.74)$ & $(-2.20)$ & & $(-1.08)$ & $(-0.89)$ \\
Log(Assets) & 0.29 & -0.31 & & -19.26 & -9.61 \\
& $(0.12)$ & $(-0.05)$ & & $(-2.85)$ & $(-0.36)$ \\
\hline Quarter FE & $\mathrm{Y}$ & $\mathrm{Y}$ & & $\mathrm{Y}$ & $\mathrm{Y}$ \\
Insurer FE & $\mathrm{N}$ & $\mathrm{Y}$ & & $\mathrm{N}$ & $\mathrm{Y}$ \\
SE clustered by & $\mathrm{I}, \mathrm{Q}$ & $\mathrm{I}, \mathrm{Q}$ & & $\mathrm{I}, \mathrm{Q}$ & $\mathrm{I}, \mathrm{Q}$ \\
$R^{2}$ & 0.09 & 0.83 & & 0.63 & 0.79 \\
Insurer-Quarters & 1,701 & 1,701 & & 1,701 & 1,701 \\
Insurers & 50 & 50 & & 50 & 50 \\
\hline
\end{tabular}


Table 3: Share of newly issued bonds bought by insurers hit hard and issue characteristics: corporate bonds

Notes: This table shows regressions of the fraction of newly issued bonds purchased by insurers hit hard by the crisis on bond characteristics. The underlying data for this is daily transaction data from 2005-2014, for corporate bonds (excluding financial issuers). Regressions are at the issue level. The dependent variable is net purchases by insurers hit hard by the crisis, within three months of the first transaction, as a fraction of net purchases by all large insurers with matched parents, in percentage points, winsorized at the 5 th and 95 th percentiles by NAIC category. The sample restricts to bonds with at least ten transactions by large insurers with matched parents. YTM is the fair value weighted yield to maturity of the bond for all transactions by life insurers (within three months of the first transaction), winsorized at the 5 th and 95 th percentiles by NAIC category. Maturity is the bond maturity in years from Dealogic. All specifications include (origination) month and (Dealogic-based) issuer fixed effects. All specifications also include (log) total purchases by large insurers (winsorized at the 5th and 95th percentiles by NAIC category), a dummy for private structured bonds, and interactions of these variables with the crisis and post-crisis dummies as controls. Standard errors are double-clustered by issuer and month. The sample for the first column is all investment grade bonds; the second and third column use only NAIC 1 and NAIC 2 bonds respectively. $t$-statistics are shown in parentheses.

\begin{tabular}{|c|c|c|c|}
\hline & All IG & NAIC 1 & NAIC 2 \\
\hline & Hit hard fraction & Hit hard fraction & Hit hard fraction \\
\hline YTM & $\begin{array}{r}12.0 \\
(4.17)\end{array}$ & $\begin{array}{r}18.5 \\
(2.13)\end{array}$ & $\begin{array}{r}8.8 \\
(1.48)\end{array}$ \\
\hline YTM × 2007Q3-2010Q4 & $\begin{array}{r}-14.9 \\
(-5.31)\end{array}$ & $\begin{array}{r}-22.5 \\
(-2.58)\end{array}$ & $\begin{array}{r}-10.6 \\
(-1.74)\end{array}$ \\
\hline $\mathrm{YTM} \times 2011 \mathrm{Q} 1-2014 \mathrm{Q} 4$ & $\begin{array}{r}-17.7 \\
(-5.91)\end{array}$ & $\begin{array}{r}-27.6 \\
(-3.14)\end{array}$ & $\begin{array}{r}-11.7 \\
(-1.95)\end{array}$ \\
\hline Maturity & $\begin{array}{r}-0.4 \\
(-2.75)\end{array}$ & $\begin{array}{r}-0.8 \\
(-2.64)\end{array}$ & $\begin{array}{r}-0.2 \\
(-0.84)\end{array}$ \\
\hline Maturity × 2007Q3-2010Q4 & $\begin{array}{r}0.8 \\
(4.95)\end{array}$ & $\begin{array}{r}1.2 \\
(3.76)\end{array}$ & $\begin{array}{r}0.7 \\
(2.40)\end{array}$ \\
\hline Maturity × 2011Q1-2014Q4 & $\begin{array}{r}0.9 \\
(5.71) \\
\end{array}$ & $\begin{array}{r}1.6 \\
(4.70)\end{array}$ & $\begin{array}{r}0.5 \\
(1.74)\end{array}$ \\
\hline Controls & $\mathrm{Y}$ & $\mathrm{Y}$ & $\mathrm{Y}$ \\
\hline Month FE & $\mathrm{Y}$ & $\mathrm{Y}$ & $\mathrm{Y}$ \\
\hline Issuer FE & $\mathrm{Y}$ & $\mathrm{Y}$ & $\mathrm{Y}$ \\
\hline SE clustered by & Iss, M & Iss, M & Iss, M \\
\hline$R^{2}$ & 0.57 & 0.57 & 0.66 \\
\hline Issues & 3,058 & 1,528 & 1,530 \\
\hline Issuers & 837 & 385 & 521 \\
\hline Transactions & 66,056 & 33,448 & 32,608 \\
\hline
\end{tabular}


Table 4: Share of newly issued bonds bought by insurers hit hard and issue characteristics: private investment grade bonds

Notes: This table shows regressions of the fraction of newly issued bonds purchased by insurers hit hard by the crisis on bond characteristics. The underlying data for this is daily transaction data from 2005-2014, for corporate bonds (including financial issuers) and private structured bonds. Regressions are at the issue level. The dependent variable is net purchases by insurers hit hard by the crisis, within three months of the first transaction, as a fraction of net purchases by all large insurers with matched parents, in percentage points, winsorized at the 5th and 95th percentiles by NAIC category. The sample restricts to bonds with at least ten transactions by large insurers with matched parents. YTM is the fair value weighted yield to maturity of the bond for all transactions by life insurers (within three months of the first transaction), winsorized at the 5th and 95th percentiles by NAIC category. Maturity is the bond maturity in years from Dealogic. All specifications include (origination) month and (Dealogic-based) issuer fixed effects. All specifications also include (log) total purchases by large insurers (winsorized at the 5th and 95th percentiles by NAIC category), and interactions of this variable with the crisis and post-crisis dummies as controls. Standard errors are double-clustered by issuer and month. The sample for the first column is all investment grade bonds; the second and third column use only NAIC 1 and NAIC 2 bonds respectively. $t$-statistics are shown in parentheses.

\begin{tabular}{|c|c|c|c|}
\hline & \multicolumn{2}{|r|}{ NAIC 1} & \multirow{2}{*}{$\frac{\text { NAIC } 2}{\text { Hit hard fraction }}$} \\
\hline & Hit hard fraction & Hit hard fraction & \\
\hline YTM & $\begin{array}{r}3.5 \\
(1.04)\end{array}$ & $\begin{array}{r}10.4 \\
(1.60)\end{array}$ & $\begin{array}{r}1.8 \\
(0.28)\end{array}$ \\
\hline YTM × 2007Q3-2010Q4 & $\begin{array}{r}-5.6 \\
(-1.66)\end{array}$ & $\begin{array}{r}-12.3 \\
(-1.89)\end{array}$ & $\begin{array}{r}-2.5 \\
(-0.40)\end{array}$ \\
\hline $\mathrm{YTM} \times 2011 \mathrm{Q} 1-2014 \mathrm{Q} 4$ & $\begin{array}{r}-9.5 \\
(-2.80)\end{array}$ & $\begin{array}{r}-18.0 \\
(-2.82)\end{array}$ & $\begin{array}{r}-5.0 \\
(-0.79)\end{array}$ \\
\hline Maturity & $\begin{array}{r}-0.3 \\
(-2.00)\end{array}$ & $\begin{array}{r}-0.7 \\
(-3.40)\end{array}$ & $\begin{array}{r}-0.0 \\
(-0.08)\end{array}$ \\
\hline Maturity × 2007Q3-2010Q4 & $\begin{array}{r}0.7 \\
(4.42)\end{array}$ & $\begin{array}{r}1.0 \\
(4.80)\end{array}$ & $\begin{array}{r}0.4 \\
(1.60)\end{array}$ \\
\hline Maturity × 2011Q1-2014Q4 & $\begin{array}{r}0.8 \\
(5.16)\end{array}$ & $\begin{array}{r}1.3 \\
(5.60)\end{array}$ & $\begin{array}{r}0.3 \\
(1.13)\end{array}$ \\
\hline Controls & $\mathrm{Y}$ & Y & $\mathrm{Y}$ \\
\hline Month FE & $\mathrm{Y}$ & $\mathrm{Y}$ & $\mathrm{Y}$ \\
\hline Issuer FE & $\mathrm{Y}$ & $\mathrm{Y}$ & $\mathrm{Y}$ \\
\hline SE clustered by & Iss, M & Iss, M & Iss, M \\
\hline$R^{2}$ & 0.55 & 0.54 & 0.66 \\
\hline Issues & 4,144 & 2,258 & 1,886 \\
\hline Issuers & 1,205 & 617 & 683 \\
\hline Transactions & 86,778 & 47,898 & 38,880 \\
\hline
\end{tabular}


Table 5: Interest-rate risk (with and without derivatives) based on crisis experience

Notes: This table shows regressions of different measures of interest-rate risk on crisis experience for large insurers with matched parents. The data is quarterly, from 2005Q1-2014Q4. I aggregate the data to the insurance group level, pro-forma based on current ownership structures. DV01 Gap including derivatives is (Liability DV01 - Bond DV01 - Derivatives DV01)/(Liability DV01), in percentage points with a cap at 100 and floor at 0. DV01 Gap excluding derivatives is (Liability DV01 - Bond DV01)/(Liability DV01), in percentage points with a cap at 100 and floor at 0. Crisis Hit Flag is an insurer-level dummy for severe dividend cuts, reduction in equity/assets ratio or equity issuance during the crisis period, as described in Section 3. All specifications include interactions of Crisis Hit Flag with dummies for the crisis (2007Q3-2010Q4) and post-crisis (2011Q12014Q4) periods. All specifications include Log(Assets), the natural logarithm of total assets, as a control for size. Standard errors are double-clustered by insurer and quarter. $t$-statistics are shown in parentheses.

\begin{tabular}{lrrrrr}
\hline & \multicolumn{2}{c}{ Including derivatives } & & \multicolumn{2}{c}{ Excluding derivatives } \\
\cline { 2 - 2 } & DV01 Gap & DV01 Gap & & DV01 Gap & DV01 Gap \\
\hline Crisis Hit Flag & 6.85 & & & 6.22 & \\
& $(1.06)$ & & & $(0.96)$ & \\
Crisis Hit Flag $\times$ 2007Q3-2010Q4 & -3.22 & -2.94 & & -0.86 & -0.53 \\
& $(-2.63)$ & $(-1.26)$ & & $(-2.39)$ & $(-0.26)$ \\
Crisis Hit Flag $\times 2011$ Q1-2014Q4 & -8.96 & -8.07 & & -4.37 & -3.29 \\
& $(-2.74)$ & $(-2.20)$ & & $(-1.41)$ & $(-0.95)$ \\
Log(Assets) & 0.29 & -0.31 & & 0.98 & -0.27 \\
& $(0.12)$ & $(-0.05)$ & & $(0.39)$ & $(-0.04)$ \\
\hline Quarter FE & $\mathrm{Y}$ & $\mathrm{Y}$ & $\mathrm{Y}$ & $\mathrm{Y}$ & $\mathrm{Y}$ \\
Insurer FE & $\mathrm{N}$ & $\mathrm{Y}$ & $\mathrm{N}$ & $\mathrm{Y}$ \\
SE clustered by & $\mathrm{I}, \mathrm{Q}$ & $\mathrm{I}, \mathrm{Q}$ & $\mathrm{I}, \mathrm{Q}$ & $\mathrm{I}, \mathrm{Q}$ \\
$R^{2}$ & 0.09 & 0.83 & & 0.09 & 0.86 \\
Insurer-Quarters & 1,701 & 1,701 & & 1,701 & 1,701 \\
Insurers & 50 & 50 & & 50 & 50 \\
\hline
\end{tabular}


Table 6: Yields and duration of purchases based on crisis experience for large insurers with matched parent

Notes: This table shows regressions of YTM (credit risk) and the average duration of bonds purchased on crisis experience for large insurers with matched parents. The data is quarterly, from 2005Q1-2014Q4. I aggregate the data to the insurance group level, pro-forma based on current ownership structures. YTM is the fair value value weighted average yield to maturity of all bonds purchased in the insurer-quarter, in basis points, winsorized at the 5th and 95th percentiles. Duration is the fair value value weighted average duration of all bonds purchased in the insurer-quarter, in years, winsorized at the 5th and 95th percentiles. Crisis Hit Flag is an insurer-level dummy for severe dividend cuts, reduction in equity/assets ratio or equity issuance during the crisis period, as described in Section 3. All specifications include interactions of Crisis Hit Flag with dummies for the crisis (2007Q3-2010Q4) and post-crisis (2011Q1-2014Q4) periods. All specifications include $\log$ (Assets), the natural logarithm of total assets, as a control for size. Standard errors are double-clustered by insurer and quarter. $t$-statistics are shown in parentheses.

\begin{tabular}{|c|c|c|c|c|}
\hline & \multicolumn{2}{|c|}{ Credit risk } & \multicolumn{2}{|c|}{ Duration of purchases } \\
\hline & YTM & YTM & Duration & Duration \\
\hline Crisis Hit Flag & $\begin{array}{l}13.64 \\
(1.15)\end{array}$ & & $\begin{array}{r}0.52 \\
(1.21)\end{array}$ & \\
\hline Crisis Hit Flag $\times$ 2007Q3-2010Q4 & $\begin{array}{l}-28.28 \\
(-2.45)\end{array}$ & $\begin{array}{l}-29.00 \\
(-2.40)\end{array}$ & $\begin{array}{r}0.69 \\
(1.90)\end{array}$ & $\begin{array}{r}0.60 \\
(1.59)\end{array}$ \\
\hline Crisis Hit Flag $\times$ 2011Q1-2014Q4 & $\begin{array}{l}-16.19 \\
(-1.08)\end{array}$ & $\begin{array}{l}-14.29 \\
(-0.89)\end{array}$ & $\begin{array}{r}-0.15 \\
(-0.30)\end{array}$ & $\begin{array}{r}-0.14 \\
(-0.27)\end{array}$ \\
\hline Log(Assets) & $\begin{array}{l}-19.26 \\
(-2.85)\end{array}$ & $\begin{array}{r}-9.61 \\
(-0.36)\end{array}$ & $\begin{array}{r}0.02 \\
(0.15)\end{array}$ & $\begin{array}{r}0.81 \\
(1.27)\end{array}$ \\
\hline Quarter FE & $\mathrm{Y}$ & $\mathrm{Y}$ & $\mathrm{Y}$ & $\mathrm{Y}$ \\
\hline Insurer FE & $\mathrm{N}$ & $\mathrm{Y}$ & $\mathrm{N}$ & $\mathrm{Y}$ \\
\hline SE clustered by & $\mathrm{I}, \mathrm{Q}$ & $\mathrm{I}, \mathrm{Q}$ & $\mathrm{I}, \mathrm{Q}$ & $\mathrm{I}, \mathrm{Q}$ \\
\hline$R^{2}$ & 0.63 & 0.79 & 0.12 & 0.46 \\
\hline Insurer-Quarters & 1,701 & 1,701 & 1,701 & 1,701 \\
\hline Insurers & 50 & 50 & 50 & 50 \\
\hline
\end{tabular}


Table 7: Risk taking based on crisis experience for all large insurers

Notes: This table shows regressions of Net DV01 Gap (interest-rate risk) and YTM (credit risk) on crisis experience for all large insurers, including those without matched parents. The data is quarterly, from 2005Q1-2014Q4. I aggregate the data to the insurance group level, pro-forma based on current ownership structures. Net DV01 Gap is (Liability DV01 - Bond DV01 - Derivatives DV01)/(Liability DV01), in percentage points with a cap at 100 and floor at 0. YTM is the fair value value weighted average yield to maturity of all bonds purchased in the insurer-quarter, in basis points, winsorized at the 5th and 95th percentiles. Crisis Hit Flag is an insurer-level dummy for severe dividend cuts, reduction in equity/assets ratio or equity issuance during the crisis period, as described in Section 3. Insurers without matched parents are classified as not hit hard by the crisis. All specifications include interactions of Crisis Hit Flag with dummies for the crisis (2007Q3-2010Q4) and post-crisis (2011Q1-2014Q4) periods. All specifications include Log(Assets), the natural logarithm of total assets, as a control for size. Standard errors are double-clustered by insurer and quarter. $t$-statistics are shown in parentheses.

\begin{tabular}{|c|c|c|c|c|}
\hline & \multicolumn{2}{|c|}{ Interest-rate risk } & \multicolumn{2}{|c|}{ Credit risk } \\
\hline & Net DV01 Gap & Net DV01 Gap & YTM & YTM \\
\hline Crisis Hit Flag & $\begin{array}{r}1.47 \\
(0.30)\end{array}$ & & $\begin{array}{r}9.92 \\
(1.01)\end{array}$ & \\
\hline Crisis Hit Flag × 2007Q3-2010Q4 & $\begin{array}{r}-1.89 \\
(-1.82)\end{array}$ & $\begin{array}{r}-1.73 \\
(-0.86)\end{array}$ & $\begin{array}{l}-20.77 \\
(-1.81)\end{array}$ & $\begin{array}{l}-20.92 \\
(-1.76)\end{array}$ \\
\hline Crisis Hit Flag × 2011Q1-2014Q4 & $\begin{array}{r}-7.73 \\
(-2.64)\end{array}$ & $\begin{array}{r}-7.35 \\
(-2.28)\end{array}$ & $\begin{array}{l}-17.22 \\
(-1.26)\end{array}$ & $\begin{array}{l}-15.74 \\
(-1.12)\end{array}$ \\
\hline Log(Assets) & $\begin{array}{r}2.61 \\
(1.29)\end{array}$ & $\begin{array}{r}1.78 \\
(0.31)\end{array}$ & $\begin{array}{l}-13.21 \\
(-2.17)\end{array}$ & $\begin{array}{r}-3.75 \\
(-0.16)\end{array}$ \\
\hline Quarter FE & $\mathrm{Y}$ & $\mathrm{Y}$ & $\mathrm{Y}$ & $\mathrm{Y}$ \\
\hline Insurer FE & $\mathrm{N}$ & $\mathrm{Y}$ & $\mathrm{N}$ & $\mathrm{Y}$ \\
\hline SE clustered by & $\mathrm{I}, \mathrm{Q}$ & $\mathrm{I}, \mathrm{Q}$ & $\mathrm{I}, \mathrm{Q}$ & $\mathrm{I}, \mathrm{Q}$ \\
\hline$R^{2}$ & 0.10 & 0.83 & 0.60 & 0.79 \\
\hline Insurer-Quarters & 2,136 & 2,136 & 2,136 & 2,136 \\
\hline Insurers & 64 & 64 & 64 & 64 \\
\hline
\end{tabular}


Table 8: Summary statistics for large banks with matched parent

Notes: This table shows summary statistics of key variables for my sample of large US banks with matched corporate parents, separated by whether I categorize them as hit hard by the crisis or not. The data is quarterly, from 2005Q1-2014Q4. I aggregate the data to the parent level, pro-forma based on current ownership structures. Assets are reported in $\$ B N$, based on data at the holding company level. Loan growth variables are changes in natural logarithms, multiplied by 100, based on data at the holding company level. Loans $>1$ Year is loans maturing or repricing in more than one year as a fraction of loans with reported maturity data, in percentage points, using call report data at the commercial bank level. The first column shows the mean for each variable in the full sample. The second column shows the mean excluding banks hit hard by the crisis. 'Hit hard' is a bank-level dummy for severe dividend cuts or reduction in equity/assets ratio, as described in Section 3. The third column shows the mean for banks hit hard by the crisis. The final column shows the standard deviation in the full sample.

\begin{tabular}{lrrrr}
\hline & Full Sample & Others & Hit hard & Std. Dev. \\
\hline Assets & 184.0 & 148.3 & 226.0 & 473.6 \\
Loan Growth & 1.1 & 1.2 & 1.0 & 2.7 \\
RE Loan Growth & 0.7 & 1.0 & 0.4 & 2.8 \\
Non-RE Loan Growth & 1.4 & 1.5 & 1.2 & 6.2 \\
Loans > 1 Year & 47.1 & 48.2 & 45.7 & 17.2 \\
\hline BHC-Quarters & 2,144 & & & \\
BHCs & 54 & & & \\
\hline
\end{tabular}


Table 9: Risk taking based on crisis experience for large banks with matched parent

Notes: This table shows regressions of RE loan growth (credit risk) and Loans $>1$ Year (interestrate risk) on crisis experience for large banks with matched parents. The data is quarterly, from 2005Q1-2014Q4. I aggregate the data to the parent level, pro-forma based on current ownership structures. Credit growth refers to changes in natural logarithms of real estate loan growth, multiplied by 100, based on data at the holding company level. Loans $>1$ Year is loans maturing or repricing in more than one year as a fraction of loans with reported maturity data, in percentage points, using call report data at the commercial bank level. Crisis Hit Flag is a bank-level dummy for severe dividend cuts or reduction in equity/assets ratio, as described in Section 3. All specifications include interactions of Crisis Hit Flag with dummies for the crisis (2007Q3-2010Q4) and post-crisis (2011Q1-2014Q4) periods. All specifications include Log(Assets), the natural logarithm of total assets, as a control for size. Standard errors are double-clustered by bank and quarter. $t$-statistics are shown in parentheses.

\begin{tabular}{|c|c|c|c|c|}
\hline & \multicolumn{2}{|c|}{ Credit risk } & \multicolumn{2}{|c|}{ Interest rate risk } \\
\hline & $\Delta \log \times 100$ & $\Delta \log \times 100$ & Loans $>1 Y r$ & Loans $>1 Y r$ \\
\hline Crisis Hit Flag & $\begin{array}{r}0.31 \\
(0.87)\end{array}$ & & $\begin{array}{r}2.23 \\
(0.57)\end{array}$ & \\
\hline Crisis Hit Flag × 2007Q3-2010Q4 & $\begin{array}{r}-1.02 \\
(-2.47)\end{array}$ & $\begin{array}{r}-1.04 \\
(-2.41)\end{array}$ & $\begin{array}{r}-0.27 \\
(-0.17)\end{array}$ & $\begin{array}{r}0.37 \\
(0.17)\end{array}$ \\
\hline Crisis Hit Flag $\times$ 2011Q1-2014Q4 & $\begin{array}{r}-0.75 \\
(-1.56)\end{array}$ & $\begin{array}{r}-0.61 \\
(-1.24)\end{array}$ & $\begin{array}{r}-6.83 \\
(-1.93)\end{array}$ & $\begin{array}{r}-6.39 \\
(-1.69)\end{array}$ \\
\hline Log(Assets) & $\begin{array}{r}-0.31 \\
(-3.45)\end{array}$ & $\begin{array}{r}1.17 \\
(2.11)\end{array}$ & $\begin{array}{r}-2.53 \\
(-2.23)\end{array}$ & $\begin{array}{r}-8.73 \\
(-2.38)\end{array}$ \\
\hline Quarter FE & $\mathrm{Y}$ & Y & $\mathrm{Y}$ & $\mathrm{Y}$ \\
\hline BHC FE & $\mathrm{N}$ & $\mathrm{Y}$ & $\mathrm{N}$ & $\mathrm{Y}$ \\
\hline SE clustered by & $\mathrm{B}, \mathrm{Q}$ & $\mathrm{B}, \mathrm{Q}$ & $\mathrm{B}, \mathrm{Q}$ & $\mathrm{B}, \mathrm{Q}$ \\
\hline$R^{2}$ & 0.22 & 0.37 & 0.07 & 0.82 \\
\hline BHC-Quarters & 2,144 & 2,144 & 2,144 & 2,144 \\
\hline $\mathrm{BHCs}$ & 54 & 54 & 54 & 54 \\
\hline
\end{tabular}


Table 10: Additional measures of loan growth based on crisis experience for large banks

Notes: This table shows regressions additional measures of credit growth on crisis experience for large banks with matched parents. The data is quarterly, from 2005Q1-2014Q4. I aggregate the data to the parent level, pro-forma based on current ownership structures. Credit growth refers to changes in natural logarithms of loan growth, multiplied by 100, based on data at the holding company level. Total loans are reported on Schedule HC, net of the allowance for loan and lease losses. Components of lending are reported on Schedule HC-C, without deducting the allowance for loan and lease losses. Crisis Hit Flag is a bank-level dummy for severe dividend cuts or reduction in equity/assets ratio, as described in Section 3. All specifications include interactions of Crisis Hit Flag with dummies for the crisis (2007Q3-2010Q4) and post-crisis (2011Q1-2014Q4) periods. All specifications include $\log$ (Assets), the natural logarithm of total assets, as a control for size. Standard errors are double-clustered by bank and quarter. $t$-statistics are shown in parentheses.

\begin{tabular}{lrrrrr}
\hline & \multicolumn{2}{c}{ Non-real estate loans } & & \multicolumn{2}{c}{ All loans } \\
\cline { 2 - 3 } & $\Delta \log \times 100$ & $\Delta \log \times 100$ & & $\Delta \log \times 100$ & $\Delta \log \times 100$ \\
\hline Crisis Hit Flag & 0.44 & & & 0.22 \\
& $(0.95)$ & & & $(0.71)$ & \\
Crisis Hit Flag $\times 2007$ Q3-2010Q4 & -1.35 & -1.41 & & -0.74 & -0.77 \\
& $(-2.26)$ & $(-2.22)$ & & $(-2.29)$ & $(-2.21)$ \\
Crisis Hit Flag $\times 2011$ Q1-2014Q4 & -0.40 & -0.10 & -0.22 & -0.17 \\
& $(-0.81)$ & $(-0.13)$ & $(-0.59)$ & $(-0.42)$ \\
Log(Assets) & -0.16 & 3.42 & -0.19 & 0.76 \\
& $(-1.14)$ & $(1.69)$ & $(-1.94)$ & $(2.02)$ \\
\hline Quarter FE & $\mathrm{Y}$ & $\mathrm{Y}$ & $\mathrm{Y}$ & $\mathrm{Y}$ \\
BHC FE & $\mathrm{N}$ & $\mathrm{Y}$ & $\mathrm{N}$ & $\mathrm{Y}$ \\
SE clustered by & $\mathrm{B}, \mathrm{Q}$ & $\mathrm{B}, \mathrm{Q}$ & $\mathrm{B}, \mathrm{Q}$ & $\mathrm{B}, \mathrm{Q}$ \\
$R^{2}$ & 0.05 & 0.11 & 0.21 & 0.35 \\
BHC-Quarters & 2,144 & 2,144 & 2,144 & 2,144 \\
BHCs & 54 & 54 & 54 & 54 \\
\hline
\end{tabular}

